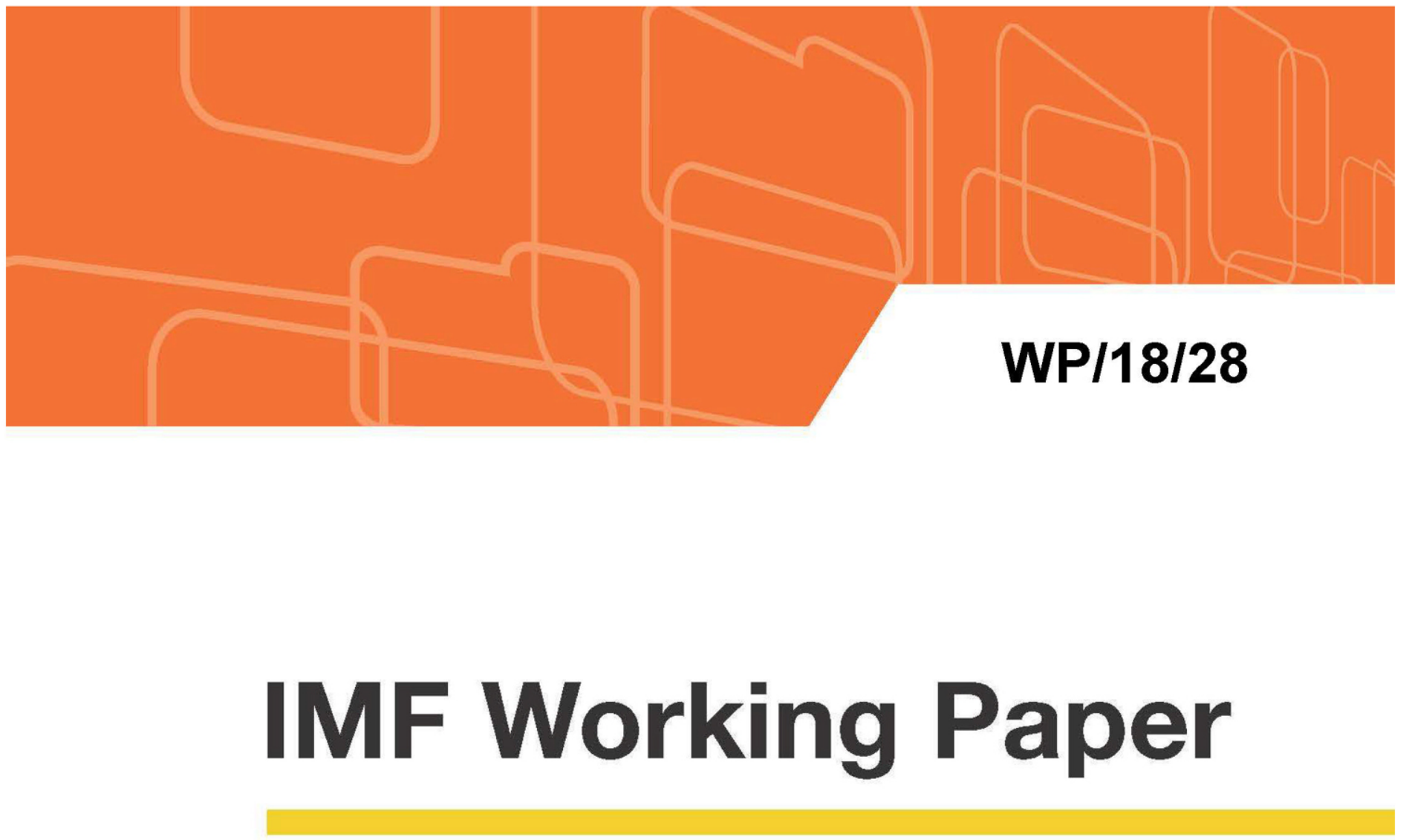

\title{
Monetary Policy and Models of Currency Demand
}

by Mariam El Hamiani Khatat

IMF Working Papers describe research in progress by the author(s) and are published to elicit comments and to encourage debate. The views expressed in IMF Working Papers are those of the author(s) and do not necessarily represent the views of the IMF, its Executive Board, or IMF management. 


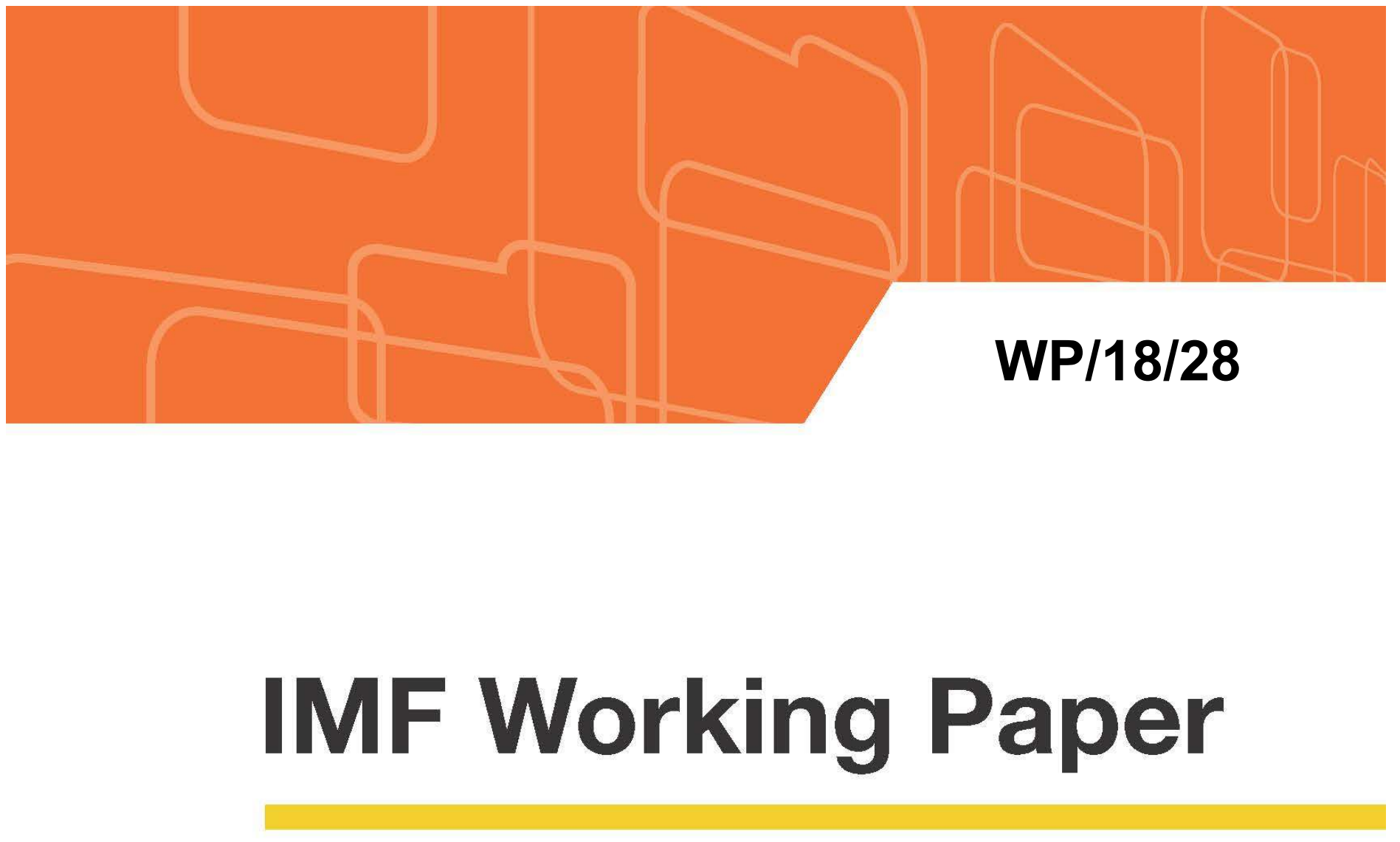

\section{Monetary Policy and Models of Currency Demand}

by Mariam El Hamiani Khatat

IMF Working Papers describe research in progress by the author(s) and are published to elicit comments and to encourage debate. The views expressed in IMF Working Papers are those of the author(s) and do not necessarily represent the views of the IMF, its Executive Board, or IMF management. 


\title{
IMF Working Paper
}

Monetary and Capital Markets Department

\section{Monetary Policy and Models of Currency Demand}

Prepared by Mariam El Hamiani Khatat ${ }^{1}$

Authorized for distribution by Ghiath Shabsigh

February 2018

\section{IMF Working Papers describe research in progress by the author(s) and are published to} elicit comments and to encourage debate. The views expressed in IMF Working Papers are those of the author(s) and do not necessarily represent the views of the IMF, its Executive Board, or IMF management.

\begin{abstract}
Two types of currency in circulation models are identified: (1) a first generation derived from the theory of money demand and (2) a second generation aimed at producing daily forecasts of currency in circulation. In this paper, we transform the currency demand function into a VAR to capture the dynamic link between interest rates and the demand for cash. We also apply ARIMA modeling to forecast the daily currency in circulation for Brazil, Kazakhstan, Morocco, New Zealand, and Sudan. Our empirical work shows that some of the conclusions in the economic literature on the impact of interest rates on the demand for currency do not necessarily hold, and that central banks would benefit from running both generations of currency in circulation models. The fundamental longer-run determinants of the demand for cash are distinct from its short-run determinants.
\end{abstract}

JEL Classification Numbers: C22, C32, C51, C53, E41, E47, E52.

Keywords: Currency in circulation, ARIMA models, seasonality, liquidity forecasting, monetary policy.

Author's E-Mail Address: melhamianikhatat@,imf.org

\footnotetext{
${ }^{1}$ The author would like to thank Ghiath Shabsigh, Steven T. Philips, Bernard J. Laurens, Carlos Fernando de Barros Serrao, Kelly Eckhold, Ashraf Khan, Claney Lattie, Pau Rabanal, and Rudy Wytenburg for their detailed comments and suggestions, as well as Karen Lee for her research assistance. The author is also grateful to Banco Central do Brasil, Bank Al-Maghrib, Bank of Sudan, National Bank of Kazakhstan, and Reserve Bank of New Zealand for their valuable collaboration and support.
} 


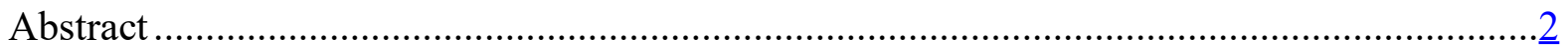

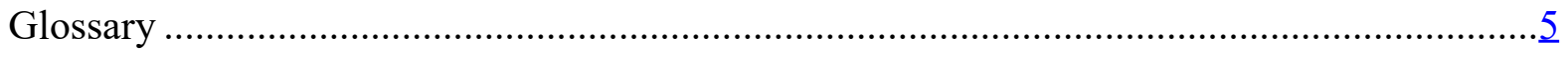

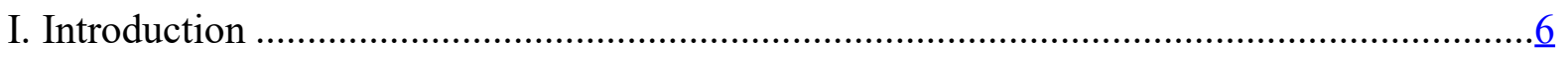

II. The Determination of the Demand for Cash ..........................................................

III. The Models for Currency in Circulation Forecasts.....................................................11

A. First Generation Models and the Theory of Demand for Money ..........................11

B. Second Generation Models in the Context of Liquidity Forecasting ......................14

IV. Currency Demand Responses to Monetary Policy Shocks: Country Experiences ............17

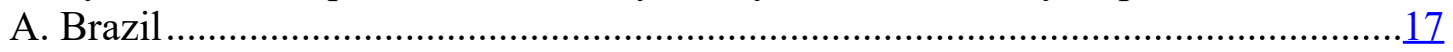

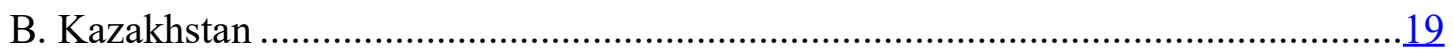

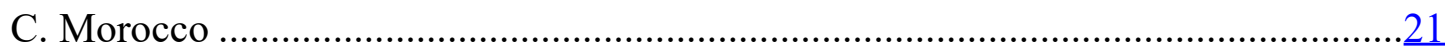

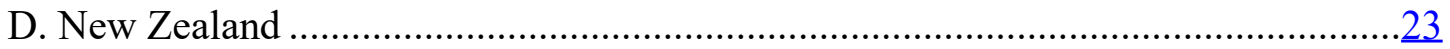

V. Modeling the Daily Currency in Circulation: Country Cases..........................................25

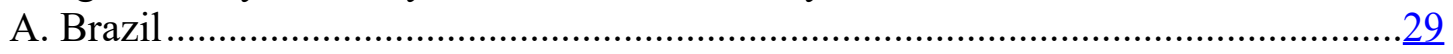

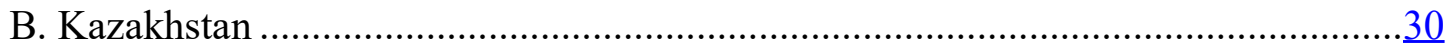

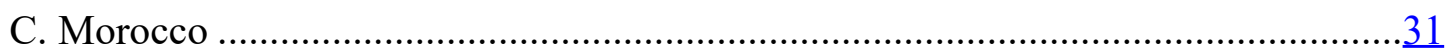

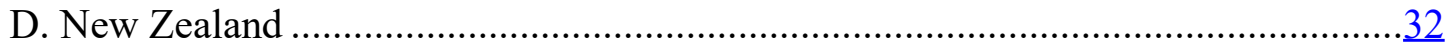

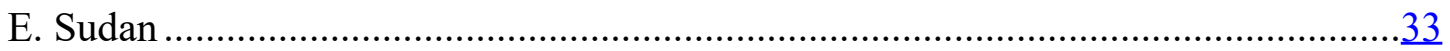

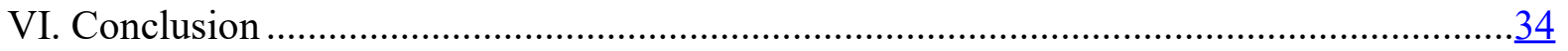

Tables

1. Currency in Circulation Models_-R-Squared and Adjusted R-Squared ...........................

Figures

1. Currency in circulation in Normal and Crisis Time................................................

2. Stylized Determinants of the Currency in Circulation..................................................11

3. Banco Central do Brasil Policy Rate (2000-16) ...........................................................

4. Brazil-Reaction of the Currency in Circulation to the Policy Rate..................................18

5. National Bank of Kazakhstan Introduction of Corridor System (2015-17) ......................20

6. Kazakhstan-Reaction of the Currency in Circulation to the Policy Rate.........................20

7. Bank Al-Maghrib Corridor System and Interbank Rate (2007-16) ................................22

8. Morocco - Reaction of the Currency in Circulation to the Policy Rate ............................22

9. Reserve Bank of New Zealand Official Cash Rate and Selected Wholesale Funding Rates

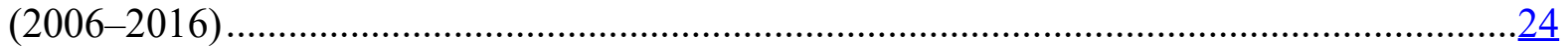

10. New Zealand-Reaction of the Currency in Circulation to the Policy Rate ....................24

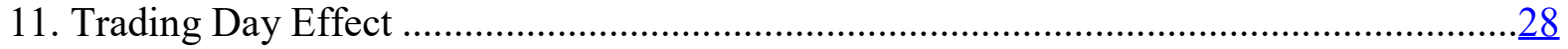

12. Beginning to Mid-week Decrease in the Currency in Circulation...................................29

13. Currency in Circulation in Brazil and New Zealand during Christmas and New Year...... $\underline{30}$ 
14. Kazakhstan Currency in Circulation Intra-Yearly Seasonality $\underline{31}$

15. Morocco and Sudan Specific Calendar Effects

Boxes

1. VAR Structure of the Currency Demand Function..........................................................13

2. Example of the Structure of the ARIMA Currency in Circulation Model ...........................16

Appendixes

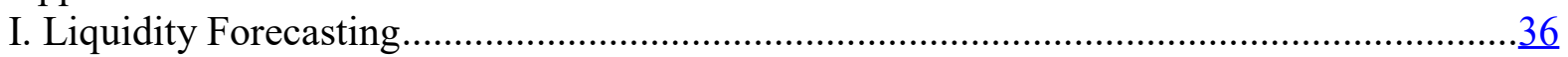

II. General Structure of the Structural Time Series Model................................................

III. Currency in Circulation - Levels and Daily Changes ......................................................

IV. Brazil ARIMA Model of Currency in Circulation - Regression Results ...........................41

V. Kazakhstan ARIMA Model of Currency in Circulation - Regression Results ...................44

VI. Morocco ARIMA Model of Currency in Circulation-Regression Results ....................... 45

VII. New Zealand ARIMA Model of Currency in Circulation-Regression Results.............. 46

VIII. Sudan ARIMA Model of Currency in Circulation-Regression Results ........................48

IX. ARIMA Model Residuals ................................................................................ 


\section{GLOSSARY}

\begin{tabular}{ll} 
AR & Auto-Regressive \\
ARIMA & Auto-Regressive Integrated Moving Average \\
ATM & Automated Teller Machine \\
BAM & Bank Al-Maghrib \\
BCB & Banco Central do Brasil \\
BoE & Bank of England \\
CIC & Currency in Circulation \\
CNB & Czech National Bank \\
COPOM & Banco Central do Brasil Monetary Policy Committee \\
CPI & Consumer Price Index \\
ECB & European Central Bank \\
EUR & Euro \\
FX & Foreign Exchange \\
GDP & Gross Domestic Product \\
IFS & International Financial Statistics \\
IMF & International Monetary Fund \\
IT & Inflation Targeting \\
KASE & Kazakhstan Stock Exchange \\
MA & Moving Average \\
NBK & National Bank of Kazakhstan \\
NCB & National Central Bank \\
NFA & Net Foreign Assets \\
NZD & New Zealand Dollar \\
OCR & Official Cash Rate \\
OLS & Ordinary Least Squares \\
OMO & Open Market Operation \\
R & Bank Reserves \\
RBNZ & Reserve Bank of New Zealand \\
REPO & Repurchase Agreement Operation \\
RR & Reserve Requirement \\
SELIC & Sistema Especial de Liquidação e de Custódia \\
SLPB & Structural Liquidity Position of the Banking System \\
STS & Structural Time Series \\
TONIA & Tenge Overnight Index Average \\
USD & US Dollar \\
VAR & Vector Autoregression \\
VECM & Vector Error Correction Model \\
YOY & Year-on-Year \\
& \\
\hline
\end{tabular}




\section{INTRODUCTION}

A number of central banks of advanced, emerging, and developing countries forecast the daily change of their currency in circulation (CIC) to calibrate the volume of their monetary operations. Yet not all central banks use models to forecast the daily CIC, and many of them still rely on expert judgment. Modeling the daily CIC improves the quality of central banks' liquidity forecasts. At the same time, central banks use several CIC models for the purpose of monetary policy, but also for their currency issuance activities. CIC forecasts over the short run rely on daily data, and on the longer run on lower frequency data (for example, monthly, or quarterly). Models based on daily frequency time series are typically used to calibrate the volume of central banks' Open Market Operations (OMOs), conducted on a regular basis. Accurate short-term (daily) forecasts help properly anticipate short-term liquidity shocks and stabilize money market rates, thereby fostering the development of money markets and strengthening monetary transmission. However, even when moving toward a more active liquidity management, it is important to retain lower frequency data models to project the central bank balance sheet over horizons beyond the short-term (from a few months to few years).

The fundamental long-run determinants of the demand for cash are distinct from its very short-term determinants. In the short run (that is, on a daily basis), the demand for currency appears to be mostly affected by recurring seasonal factors such as weekends, payroll dates, and holidays. Over the longer run, the main determinants of the demand for cash includeamong others - economic activity, inflation, the interest rate, financial crises, innovations in the payment systems as well as the exchange rate. While drivers of banking system liquidity may differ from one economy to another, the short-run determinants of the demand for cash display significant similarities across countries.

The drivers of banking system liquidity depend on: (1) the country's monetary and foreign exchange (FX) policy; (2) the magnitude of capital flows and current account shocks; (3) the capacity of the central bank to efficiently manage banking system liquidity; (4) the nature of the government budget financing and effectiveness of the government cash management; (5) the size of other items of central banks' balance sheets; (6) the structure of the financial system; and (7) the magnitude of the lender-of-last-resort operations. Yet during specific periods of time, in particular the post-global financial crisis period, many emerging and developing countries have displayed similar patterns, characterized by reversals of overall liquidity conditions, in response to capital flow reversals or current account shocks.

In such context, distinguishing liquidity shocks stemming from short-term fluctuations of autonomous factors ${ }^{2}$ from those induced by large and persistent exogenous shocks or internal

\footnotetext{
${ }^{2}$ Autonomous factors (or autonomous liquidity factors) are components of the central bank balance sheet other than its monetary policy operations and banks reserves. They are called autonomous because they are outside the control of the central bank (Cabrero, Camba-Mendez, Hirsh, and Nieto (2002)), and the main role of the liquidity management is often to offset the liquidity shocks induced by autonomous factors fluctuations.
} 
idiosyncrasies can help improve the conduct of monetary policy, regardless of the monetary policy and exchange rate regime in place.

The outstanding amount of currency issued by the central bank - that is, the CIC - is typically one of the main determinants of the structural liquidity position of the banking system (SLPB), ${ }^{3}$ together with the central bank's net foreign assets (NFA) and the net deposits of the government at the central bank. While central banks have the exclusive right to issue banknotes and coins, changes in the CIC are usually driven by the demand of economic agents and are therefore usually considered an autonomous liquidity factor. Nonetheless, in a few cases, some central banks have attempted to control or restrict the supply of cash to the economy. CIC is usually, on trend, a liquidity-absorbing factor since the issuance of CIC is mirrored by a reduction in bank reserves. ${ }^{4}$ However, changes in the trend of the CIC may occur in times of crisis. In cash-based economies, CIC swings are expected to have a stronger liquidity effect. Nonetheless, CIC can also become the autonomous factor with the most important liquidity effect in economies with flexible exchange rates, low levels of NFA, and low and stable government deposits at the central bank.

This paper provides a framework for modeling and forecasting the daily CIC. For this, it reviews the $\mathrm{CIC}$ models used by central banks and identifies two types: (1) a first generation based on the theory of transaction and portfolio demand for money, and (2) a second generation developed by central banks to produce daily CIC forecasts in the context of the management of banking system liquidity. Though the focus of the paper is more on the second generation of models, it emphasizes the need to continue to use the first generation of models. In this paper, we transform the currency demand function in a vector autoregression (VAR) to capture the dynamic link between interest rates (that is, the policy rate) and the demand for cash in Brazil, Kazakhstan, Morocco, and New Zealand. We also apply autoregressive integrated moving average (ARIMA) modeling to daily CIC for the same countries as well as Sudan. The remainder of the paper is structured as follows: section II discusses the main determinants of the demand for cash; section III introduces the models for CIC forecasts; section IV provides an empirical assessment of the reaction of the CIC to monetary policy shocks; section V presents an application of ARIMA models for Brazil, Kazakhstan, Morocco, New Zealand, and Sudan; and section VI concludes.

\section{The Determination OF THE DEMAND FOR CASH}

A number of factors can potentially affect the demand for cash, ${ }^{5}$ not only economic and financial, but also political, cultural, and technological. Income, prices, and interest rates-

\footnotetext{
${ }^{3}$ The SLPB is defined in Appendix I.

${ }^{4}$ Cabrero, Camba-Mendez, Hirsh, and Nieto (2002).

5 In this paper, "currency demand" or "demand for cash" generally refers to the stock of the CIC in the liability side of the central bank's balance sheet. In some cases, banknotes in circulation are used as a proxy for CIC.
} 
that proxy the opportunity cost of holding cash-have been traditionally and early identified as the main drivers of the demand for cash. Lower interest rates reduce the opportunity cost of holding currency, therefore increasing the relative attractiveness of cash. Economic growth tends to boost the transaction demand for currency. In many countries, the CIC usually displays a growing trend reflecting the expansion of the economic activity. Recessions and crises affect this trend, especially when depositors are concerned by the liquidity or solvency of some depository institutions. The public perception of the banking system's overall soundness influences the demand for cash, and a history of banking crises can durably undermine the confidence in banks and the perception of the relative safety of banks' accounts in comparison to cash. ${ }^{6}$

During the early phase of the global financial crisis, a slowdown in the US dollar CIC growth rate was observed, followed by a spike in 2009 and again in 2011. A surge in euro banknotes in circulation also followed the bankruptcy of Lehman Brothers and the worsening of the crisis. The insolvency of Lehman Brothers in autumn 2008 and the subsequent loss of confidence in banks' soundness led to sizeable cash withdrawals: euro banknotes served as a safe haven then. In October 2008 about half of the net withdrawals of EUR 35 billion went to regions outside the euro area. The opposite occurred during the debt crises in Greece and Cyprus: mistrust in the stability of the euro led to a decrease in international demand for euro currency between April 2010 and March 2013 (Figure 1). ${ }^{7}$

Technological change in the area of payment systems also impacts CIC trends in several, and not always linear, ways. The intuition that an increase of automated teller machines (ATMs) occurring simultaneously with innovation in payment systems would result in the reduction in currency demand is not always valid. For instance, a rise in the number of bank branches or ATMs tends to reduce the need for holding cash, but also makes cash more easily accessible, ${ }^{8}$ and an increase in the number of ATMs does not always alter consumers' preference for holding cash. ${ }^{9}$ Hence, factors such as the availability or popularity of alternative stores-of-value or payment methods, as well as consumers' preference for holding cash instead of payment alternatives, influence the CIC.

The way the central bank decides on how it breaks down the overall CIC can, in turn, affect the demand for cash, both domestically and externally. In May 2010 currency exchange offices in the UK were banned from selling EUR 500 banknotes because of their alleged use

\footnotetext{
${ }^{6}$ Della Valle and others, forthcoming.

${ }^{7}$ Mersch (2014), https://www.ecb.europa.eu/press/key/date/2014/html/sp140519.en.html.

${ }^{8}$ Gerst and Wilson (2011).

${ }^{9}$ In New Zealand, for example, the increase of ATMs in the 1990s had made cash more accessible to the public, and it is more likely that the overall demand for cash should have increased as a result of the technological innovation in the payment system rather than the contrary (Cassino, Misich, and Barry, 1997).
} 
for money laundering. ${ }^{10}$ On May 4, 2016, the Governing Council of the European Central Bank (ECB) decided to permanently stop producing the EUR 500 banknote and to exclude it from the Europa series, taking into account concerns that this banknote could facilitate illicit activities. The issuance of the EUR 500 will be stopped around the end of 2018, when the introduction of the EUR 100 and EUR 200 banknotes is planned. In view of the international role of the euro and the widespread trust in its banknotes, the EUR 500 will remain legal tender and can therefore continue to be used as a means of payment and store of value. ${ }^{11}$

When modeling and forecasting the overall CIC in the context of monetary policy activities, the central bank aims to assess the total demand for cash, but the way it then chooses the relevant denominations and coin-note boundary can also affect the public's subsequent preference. Therefore, central banks often maintain CIC models for different types of banknotes in their cash-issuance-related activities. However, from a monetary policy implementation perspective, it is the overall demand for cash that is considered as an autonomous factor, and that constitutes the focus of this paper.

Currency substitution can increase the volatility of currency demand as a result of shifts between domestic and foreign currency. These shifts can be driven by political instabilities or exchange rate expectations, as revealed by the experiences of countries such as Kazakhstan, Nigeria, Surinam, and Ukraine. In Kazakhstan, devaluation expectation episodes led to shifts from domestic to FX currency, inverting the positive trend of the CIC (Figure 1). In Nigeria, $\mathrm{CIC}$ is also sensitive to the exchange rate due to currency substitution in times of high inflation and inflation expectations. ${ }^{12}$ More generally, political instability, corruption, and weak confidence in countries' institutions and banking sector, as well as a sizeable informal economy, can induce a significant increase in the demand for cash. Currency substitution can also affect the country that issues the foreign currency. However, the effect on the country that issues the parallel currency is generally smaller than the effect on the country that uses the parallel currency, since only a small fraction of its currency is affected. ${ }^{13}$

In most countries, the CIC displays relatively stable and strong seasonal patterns. The intraweekly, intra-monthly, and intra-yearly seasonalities reflect regularities in payments and receipts (payrolls, pensions, and so on), as well as patterns in the consumption behavior associated with holidays. Usually, the CIC tends to increase just before the weekend and decreases after (intra-weekly seasonality). It increases as a result of salary payments (intramonthly seasonality). It also rises during holidays and toward the end of the year (intraannual seasonality). Common calendar effects associated with holidays include those related

\footnotetext{
${ }^{10}$ Hellerstein and Ryan (2011).

${ }^{11} \mathrm{https} / / /$ www.ecb.europa.eu/press/pr/date/2016/html/pr160504.en.html.

${ }^{12}$ Ikoku (2014).

${ }^{13}$ Schaechter (2000).
} 
to Christmas and the Gregorian New Year. However, other specific calendar effects exist in countries that do not strictly follow the Gregorian calendar, or where CIC is affected by specific religious holidays attached to other calendars such as the Muslim, Hindu, and Buddhist calendars. Specific calendar effects include, for example, those of the two main Muslim religious holidays: Eid Al-Adha and Eid Al-Fitr (Figure 15). In countries where tourism accounts for an important share of the economic activity a particularly significant increase in the CIC occurs during the summer holidays. Considering the different seasonal patterns and multiple calendar effects, specific challenges arise when attempting to model the CIC on a daily basis. These challenges have not constrained central banks from developing sophisticated models to forecast the daily changes of the CIC. Figure 2 summarizes the main determinants of the demand for cash.

Figure 1. Currency in circulation in Normal and Crisis Times

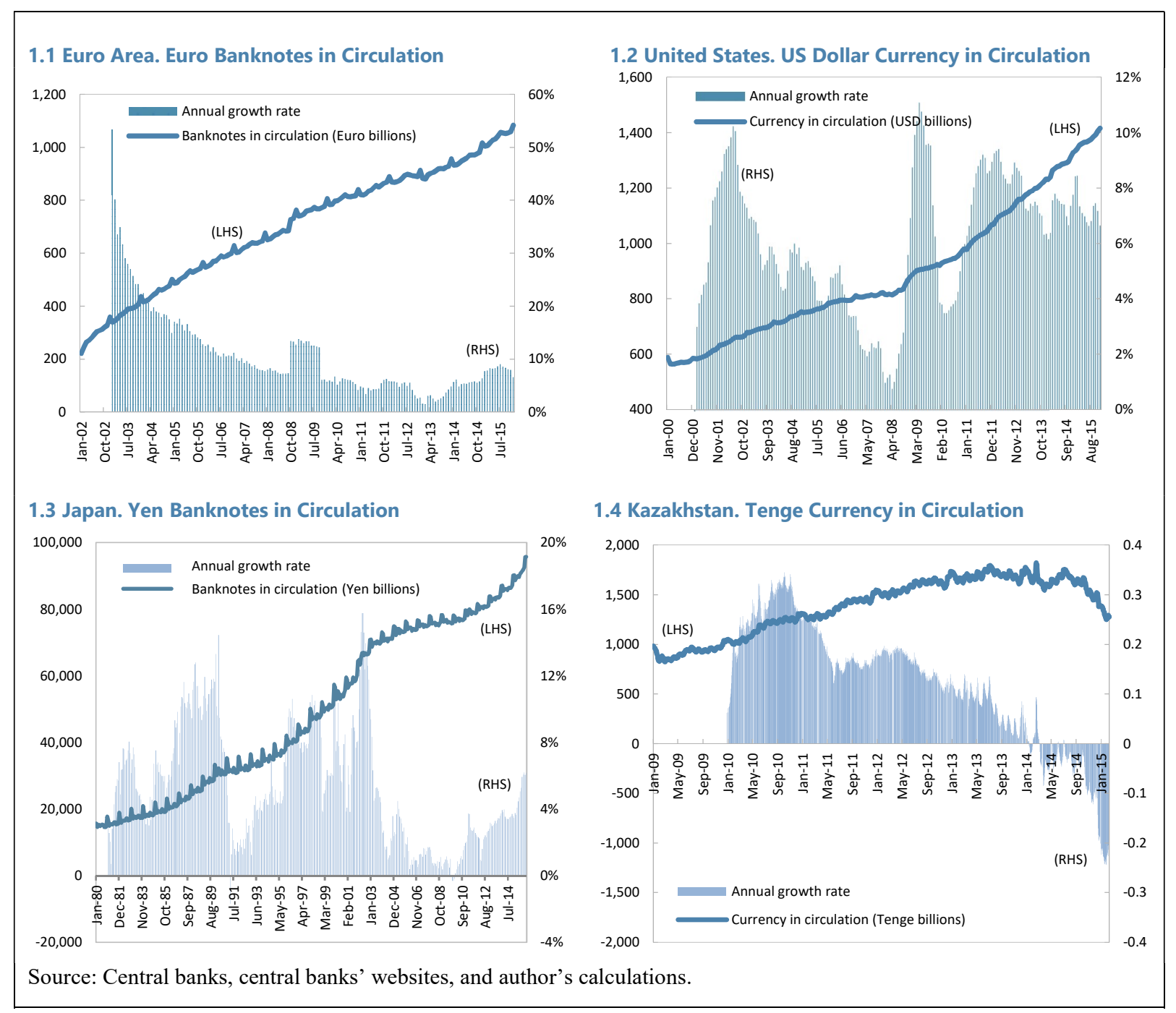


Figure 2. Stylized Determinants of the Currency in Circulation

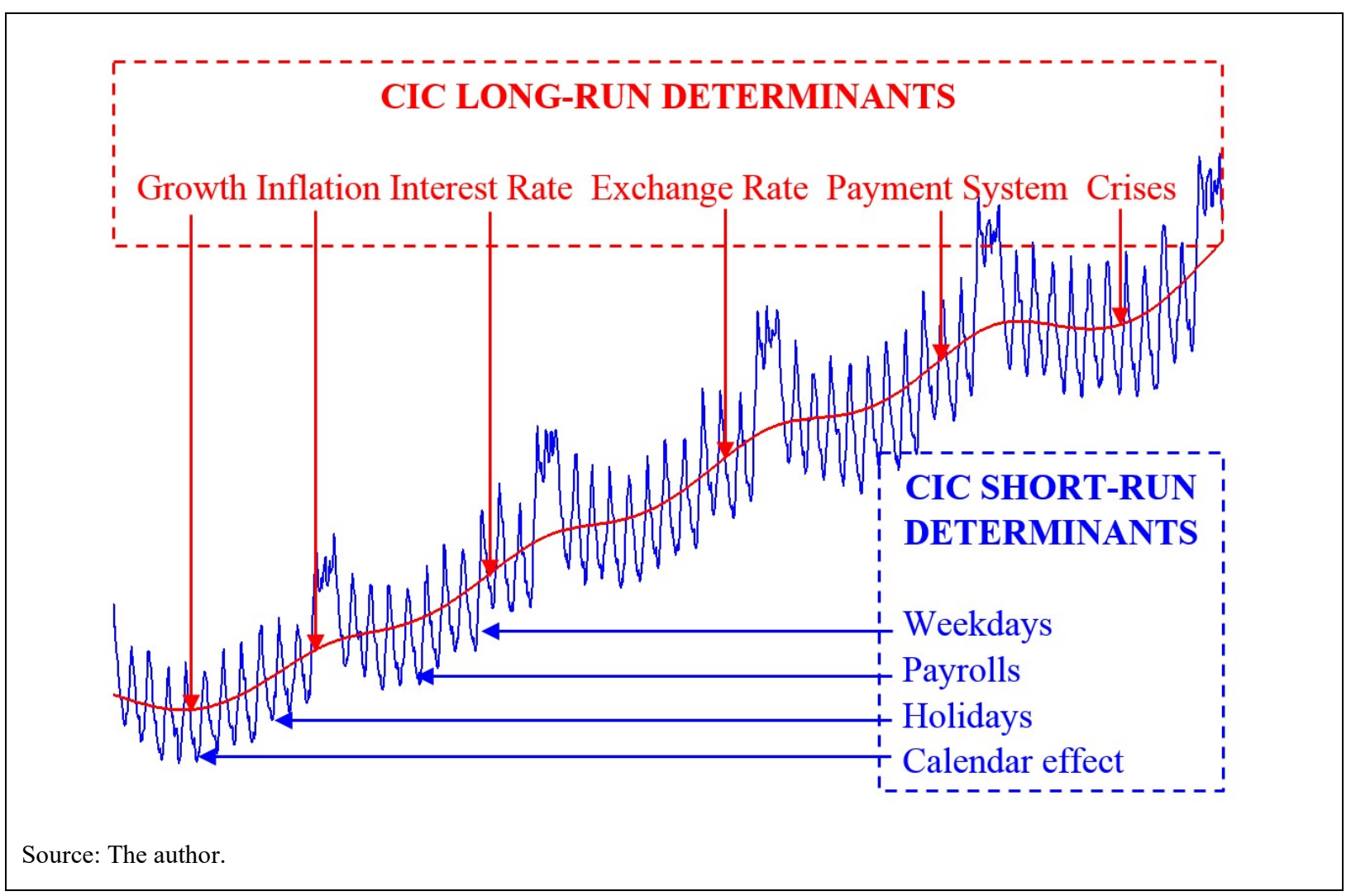

III. The Models for CuRRenCY IN CirCulation ForeCaStS

\section{A. First Generation Models and the Theory of Demand for Money}

First generation models are based on low frequency data; they rely on the theory of transaction and portfolio demand for money. According to the theory, economic agents tend to hold both cash and fixed income assets, mainly due to their desynchronized expenditures and receipts. The demand for cash departs from the need of transaction, but also depends on the opportunity cost of holding cash, that is, the opportunity cost of not storing the currency in interest-bearing assets. Higher interest rates incentivize economic agents to hold less cash. Therefore, economic agents tend to hold a mixed portfolio of cash and assets. ${ }^{14}$ Two broad approaches have been used by central banks to model the CIC based on low frequency data:

- In the first approach, the demand for money or cash $M^{d}$ in period $t$ is a function of prices $\mathrm{P}$, output $\mathrm{Y}$, and the opportunity cost of holding cash $R$ (for example, the interest rate):

$$
M_{t}^{d}=f\left(P_{t}, Y_{t}, R_{t}\right)
$$

\footnotetext{
${ }^{14}$ Tobin (1956).
} 
- In the second approach, the ARIMA technique is used. ARIMA models can be independent of any particular economic theory and combine two regression processes: an auto-regressive (AR) process, which assumes that the dependent variable is a function of its own past values, and a moving average (MA) process, allowing the inclusion of persistent random shocks.

A comparison of the two approaches for New Zealand indicates that the first approach outperforms the second one in sample, while the second outperforms the first out of sample. ${ }^{15}$

More sophisticated first generation models expand traditional models of currency demand to include other variables such as dummy variables that account for financial crises and other specific, isolated events, as well as payment system variables (number of ATMs, bank branches, and so on). However, this type of model usually aims to identify the main determinants of the currency demand rather than produce forecasts for the purpose of monetary policy implementation. Cusbert and Rohling (2013) estimated such a model for Australia. The authors found that the increase in currency holdings in late 2008 was substantially larger than what can be attributed to the normal response to the interest rate cuts and the fiscal stimulus: around 20 percent of the increase can be attributed to the normal response of currency holdings to the decrease of interest rates and the increase in income following the fiscal stimulus; the remaining 80 percent was potentially for precautionary holdings in response to the financial turmoil. Gerst and Wilson (2011) also provided a detailed analytical framework for the demand for Federal Reserve cash services; they focused on the long-term outlook for cash demand that entails different empirical approaches than those used for short-term forecasting.

A central bank's reliance on OMOs when moving toward more active liquidity management requires daily monitoring and forecasting of autonomous factors, hence the CIC, based on high-frequency (daily) time series, which are typically not available for macroeconomic variables such as output and inflation. Even when the central bank conducts its main OMOs or manages liquidity on weekly frequency, the daily modeling allows a closer monitoring of the liquidity situation, as the central bank may need to use fine-tuning operations if the daily monitoring indicates a significant forecasting error or warns of an extraordinary liquidity shock. ${ }^{16}$ When attempting to model the daily CIC, other specific challenges can arise, such as the intra-monthly and intra-weekly seasonal patterns. Yet, when moving toward a more interest-rate-based monetary policy, it is important to retain CIC models based on lower frequencies time series since daily frequency models may fail to provide reliable forecasts over horizons beyond a few days. Therefore, forecasting CIC over quarters or years may require models based on similar frequencies. Because central banks can absorb and provide

\footnotetext{
${ }^{15}$ Cassino, Misich, and Barry (1997).

${ }^{16}$ Cabrero, Camba-Mendez, Hirsh, and Nieto (2002).
} 
liquidity on the short run and the longer run, it is important to retain models based on lower frequency, as they help forecast the SLPB and project the central bank balance sheet over longer maturities.

The most recent context of negative interest rates raises additional questions about reliance on high-frequency data models only, and may revive the interest in the first generation type of models. To this end, we transform the currency demand function in a VAR form including the same variables. Simple macroeconomic models that take the form of an ordinary least square (OLS) regression can be based on assumptions that do not capture all the explanatory variables or do not take into account the significance of variables lags or consider certain variables as exogenous. Therefore, the dynamic interactions between variables is usually insufficiently represented in simple regression models and the conclusions from such models incomplete. The general form of the VAR estimated in this paper is presented in Box 1. All the variables included are considered endogenous. For the estimations, we follow similar order of variables as suggested in Christiano, Eichenbaum, and Charles (2005): gross domestic product (GDP), inflation, interest rate, and the CIC. We use the cases of Brazil, Kazakhstan, Morocco, and New Zealand to empirically explore the interest rate-CIC relation. VAR estimations and results are presented in Section IV. ${ }^{17}$

\section{Box 1. VAR Structure of the Currency Demand Function}

\section{Matrix Structure:}

$$
\left[\begin{array}{c}
y_{t} \\
\pi_{t} \\
i_{t} \\
m_{t}
\end{array}\right]=\left[\begin{array}{c}
c_{y} \\
c_{\pi} \\
c_{i} \\
c_{m}
\end{array}\right]+\left[\begin{array}{c}
a_{y, 1}^{1} a_{y, 2}^{1} a_{y, 3}^{1} a_{y, 4}^{1} \\
a_{\pi, 1}^{1} a_{\pi, 2}^{1} a_{\pi, 3}^{1} a_{\pi, 4}^{1} \\
a_{i, 1}^{1} a_{i, 2}^{1} a_{i, 3}^{1} a_{i, 4}^{1} \\
a_{m, 1}^{1} a_{m, 2}^{1} a_{m, 3}^{1} a_{m, 4}^{1}
\end{array}\right]\left[\begin{array}{c}
y_{t-1} \\
\pi_{t-1} \\
i_{t-1} \\
m_{t-1}
\end{array}\right]+\ldots+\left[\begin{array}{c}
a_{y, 1}^{p} a_{y, 2}^{p} a_{y, 3}^{p} a_{y, 4}^{p} \\
a_{\pi, 1}^{p} a_{\pi, 2}^{p} a_{\pi, 3}^{p} a_{\pi, 4}^{p} \\
a_{i, 1}^{p} a_{i, 2}^{p} a_{i, 3}^{p} a_{i, 4}^{p} \\
a_{m, 1}^{p} a_{m, 2}^{p} a_{m, 3}^{p} a_{m, 4}^{p}
\end{array}\right]\left[\begin{array}{c}
y_{t-p} \\
\pi_{t-p} \\
i_{t-p} \\
m_{t-p}
\end{array}\right]+\left[\begin{array}{c}
\varepsilon_{y, t} \\
\varepsilon_{\pi, t} \\
\varepsilon_{i, t} \\
\varepsilon_{m, t}
\end{array}\right]
$$

\section{Where:}

$y_{t}$ is the year-on-year (yoy) change in nominal GDP at time $t$

$\pi_{t} \quad$ is the yoy inflation at time $t$

$i_{t} \quad$ is the central bank main policy rate at time $t$

$m_{t} \quad$ is the yoy change of the CIC at time $t$

$c_{v} \quad$ is the constant of the regression of the dependent variable $v$

$a_{v, j}^{l} \quad$ are the regression coefficients

$\varepsilon_{v, t} \quad$ is the error term of the dependent variable $v$ at time $t$

\footnotetext{
${ }^{17}$ Section IV only discusses the CIC response to monetary policy shocks and not inflation response to an increase in the policy rate.
} 


\section{B. Second Generation Models in the Context of Liquidity Forecasting}

Models based on daily frequency time series of CIC are used to forecast the daily fluctuations of bank reserves over the maturity of the central bank standard OMOs as well as over the reserve maintenance period. Time series models have been widely used by central banks, with many of them having similar characteristics. To the best of our knowledge, ARIMA models including dummy variables to account for the different seasonal patterns and calendar effects seem to be one of the most common. ${ }^{18}$ The ECB and the Bank of England (BoE) also use Structural Time Series (STS) models. Forecasts of the CIC can be obtained by combining the forecasts of different types of statistical models - for example, ARIMA and STS—as well as with expert judgment.

The ARIMA models developed by central banks combine a dummy variable regression with an ARIMA process, consistent with the view that the CIC is a random variable following a compound process with seasonal and stochastic components. ${ }^{19}$ The deterministic component of the model describes the different seasonal patterns using several dummy variables, while the stochastic component is modeled using AR and MA processes. In addition, the use of trigonometric functions can help capturing some of the patterns, especially the intra-monthly deterministic pattern, and may help reduce the number of dummies used. ${ }^{20}$ An example of the general structure of such ARIMA models is presented in Box 2. Rather than decomposing the time series in its deterministic and stochastic components, STS modeling consists of separating the stochastic trend, cycle, and seasonal components of a time series and specifying a structural equation for each component. The general structure of the STS model is provided in Appendix II. ${ }^{21}$

ARIMA models of CIC usually include a wide range of dummies as key components, but not all of the explanatory variables are kept for the forecast; only statistically significant variables are maintained. CIC ARIMA models should fulfill standard criteria of stationarity of the dependent variable, minimal serial correlation of residuals, and good in-sample

\footnotetext{
${ }^{18}$ Among others, the following central banks rely on such models and/or have published papers using them: Bank Al-Maghrib (BAM), Banque de France, Central Bank of Nigeria, Central Bank of Sri Lanka, Croatian National Bank, Czech National Bank (CNB), European Central Bank (ECB), National Bank of Kazakhstan (NBK), National Bank of Poland, and Qatar Central Bank.

${ }^{19}$ Hlaváček and others (2005).

${ }^{20}$ An alternative specification of the intra-monthly effect takes the form of a trigonometric function which fits the deterministic seasonal patterns: $d_{t}=\sum_{j=1}^{p}\left(a_{j} \sin \frac{2 \pi j m_{t}}{M_{t}}+b_{j} \cos \frac{2 \pi j m_{t}}{M_{t}}\right)$ where $m_{t}$ stands for the day of the month and $M_{t}$ is the total number of days of a given month. $\mathrm{p}$ defines the number of different frequencies used in modeling the intra-monthly effect and should be large enough for this variable to account for all the seasonality.

${ }^{21}$ For more details on STS models, see Cabrero and others (2002), Norat (2008), and Appendix II.
} 
characteristics and forecasting properties. First order difference of the stock of the CIC is commonly used to stationarize the series.

A specification of ARIMA models with dummy variables was produced for the euro area and published in 2002. Cabrero and others (2002) applied two major statistical approaches for modeling the daily volume of banknotes in circulation in the euro area: the ARIMA approach of Bell and Hillmer (1982) and the STS model proposed by Harvey, Koopman, and Riani (1997). ${ }^{22}$ The authors compared the performance of the two models as well as the aggregated forecasts computed by the National Central Banks (NCBs). Combinations of forecasts derived from the different models were also built. The authors found that overall the combination of statistical model forecasts outperforms the aggregated forecasts obtained from the NCBs. The ARIMA model has the best forecasting performance over horizons of five days, while the STS model performs better over one- to four-day horizons. Since 2006 the BoE also has used a STS model similar to one of the ECB to forecast the demand of banknotes in the UK (Norat, 2008).

Hlaváček and others (2005) applied both ARIMA and a new neural network model—the feedforward structured neural network, which has not been applied to time series analysis and forecasting before- to the CIC in the Czech Republic. The out-of-sample performance of the models developed by the CNB shows that both models outperform the previous forecasts based on expert knowledge. According to the authors, the neural network model is slightly more accurate than the ARIMA model, mainly due to its nonlinear characteristic that is supposed to fit the seasonal patterns of the CIC more accurately. However, comparison of predictive accuracy with the use of a Diebold-Mariano test ${ }^{23}$ didn't show a statistically significant difference between the forecasts produced by these two models.

In 2006, Dheerasinghe modeled the CIC for Sri Lanka for daily, weekly, and monthly data using an ARIMA model combined with a regression on time in order to model the trend as well as the use of dummy variables. Lang and others (2008) applied ARIMA modeling with dummies to the daily currency outside banks in Croatia and found that the model outperforms the preexisting forecasts based on expert knowledge. Balli and Elsamadisy (2010) also used the ARIMA technique to model the CIC issued by Qatar Central Bank and found persistent significant effects of major religious events related to the Muslim calendar, that is, Eid AlAdha and Eid Al-Fitr. Koziński and Świst (2015) applied the ARIMA model with dummy variables to forecast the CIC in Poland.

While forecasts obtained from ARIMA models are usually found to outperform those based on pure expert knowledge, the combination of ARIMA forecasts with expert judgment is warranted, especially around the periods of significant and unexpected change in the CIC.

\footnotetext{
${ }^{22}$ Cabrero, Camba-Mendez, Hirsh, and Nieto (2002).

${ }^{23}$ Diebold and Mariano (1995).
} 
Certain seasonal patterns or exceptional events may not be perfectly captured by the structure of the model. ARIMA models in particular fail to accurately predict exceptional events. No matter how good the forecasting performance of a model is, models may not substitute expert knowledge perfectly. They are intended to provide the forecaster with a baseline that needs to be assessed and complemented or corrected to ensure that the baseline forecast fits the forecaster's own knowledge of the CIC behavior at a given point in time. By incorporating forward-looking information into the forecasts, the forecaster's intervention has a value added. ${ }^{24}$ Hence, changes in the CIC need to be adequately monitored and corrected ex-ante by expert judgment whenever deemed necessary and ex-post by re-estimations and adjustments of the CIC model. The statistical significance of the variables changes over time according to changes affecting the structure of the CIC, and a significant variable at a given point in time, can run out of explanatory power later. It is thus important to periodically reestimate the model (at least once a year). Further, an update of the CIC data and forecast on a regular basis is necessary at least before the meeting of each committee that makes the decision on the volume of the central bank's main OMOs.

\footnotetext{
Box 2. Example of the Structure of the ARIMA Currency in Circulation Model$$
\Delta y_{t}=\sum_{i=1}^{5} \alpha_{i} D_{i t}+\sum_{i=1}^{k} \beta_{i} W_{i t}+\sum_{i=1}^{4} \delta_{i} P_{i t}+\sum_{i=1}^{12} \gamma_{i} M_{i t}+\sum_{i=1}^{l} \Theta_{i}(B) H_{i t}+\Phi(B) S_{t}+\sum_{i=1}^{m} \eta_{i} O_{i t}+\sum_{i=1}^{p} \mu_{i} \Delta y_{t-i}+\sum_{i=0}^{q} \theta_{i} \varepsilon_{t-i}
$$

Where:

$y_{t} \quad$ is the CIC at time $t$

$D_{i t} \quad$ is a dummy variable that takes the value of 1 if the day at time $t$ is $i$ ( $i=$ Monday, ..,Friday) and 0 otherwise

$W_{i t} \quad$ is a dummy variable that takes the value of 1 during week $i$ of the year and 0 otherwise

$k \quad$ is the number of weeks in the year

$P_{\text {it }} \quad$ is the dummy variable that reflects the position of the week within a specific month; it takes the value of 1 when the position of the week is $i(i=1, \ldots, 4)$ in a given month and 0 otherwise

$M_{i t} \quad$ is the dummy variable that takes the value of 1 during month $i$ of the year and 0 otherwise

$B \quad$ is the standard backshift operator $\left(B y_{t}=y_{t-1}\right)$

$\Theta_{i}(B) \quad$ is a polynomial in variable B. The term $\Theta_{i}(B) H_{i t}$ captures the change of the CIC around the holiday $i$

$H_{i t} \quad$ is the dummy variable that takes the value of 1 when it is a public holiday at time $t$ and 0 otherwise

$l \quad$ is the number of calendar variation effects

$S_{t} \quad$ is the dummy variable that takes the value of 1 if salaries are paid at time $t$ and 0 otherwise

$\Phi(B) \quad$ is a polynomial in variable B. The term $\Phi(B) S_{t}$ captures the change of the ClC around the salary's payment day

$O_{i t} \quad$ are dummy variables controlling for the effect of outliers identified

$\varepsilon_{t} \quad$ is an independent and identically distributed (iid) stochastic process with zero mean and a variance of $\sigma^{2}$
}

\footnotetext{
${ }^{24}$ Norat (2008).
} 


\section{Currency Demand Responses to Monetary Policy Shocks: Country EXPERIENCES}

According to the economic theory, the currency demand is expected to have an inverse relationship with the interest rate: it is expected to decrease/increase with the increase/decrease of interest rates. To explore this relation empirically, we estimate VARs for Brazil, Kazakhstan, Morocco, and New Zealand, including the same variables as the currency demand function. The VARs and results are presented in the following subsection. Due to the fully fledged Islamic banking system and unavailability of quarterly GDP data, VARs investigating CIC response to monetary policy shocks are not estimated for Sudan in this working paper. $^{25}$

\section{A. Brazil}

Banco Central do Brasil (BCB) adopted an inflation-targeting (IT) framework in June 1999. The annual inflation targets are established by the National Monetary Council, composed of the Minister of Finance (chairman), the Governor of the BCB, and the Minister of Planning and Budget. The inflation target for 2016 was 4.5 percent with a tolerance range of 2 percentage points above and below the target. This tolerance range was reduced to 1.5 percentage points for 2017 and 2018.

The operational target of the BCB's monetary policy framework is the overnight secured interest rate, that is, the Selic rate. This is the weighted average of the interest rate charged on overnight repurchase agreement operations (repo) collateralized by public debt securities registered at Sistema Especial de Liquidação e de Custódia (Selic). ${ }^{26}$ The policy rate-that is, the target for the Selic rate - is set by the BCB's Monetary Policy Committee, the COPOM (Figure 3). The COPOM holds eight regular meetings per year, each of which lasts two days (Tuesday and Wednesday). The operational framework of the BCB includes: (1) short-term repos and reverse repos (in general, overnight) for daily liquidity management; (2) medium-term reverse repos with maturities up to 45 days, between COPOM meetings; (3) long-term reverse repos (three and six months); and (4) outright purchase/sale of domestic government debt securities.

To explore the currency demand-interest rate relation in Brazil, we transform the currency demand function in a VAR including four endogenous variables: the yoy GDP growth (GDP_YOY), the yoy inflation (INFLATION_YOY), the policy rate (POLICY_RATE), and the yoy growth rate of the CIC (CIC_YOY). The VAR is estimated using quarterly data over the period 2000:Q1-2014:Q3. The impulse response of the CIC_YOY to a POLICY_RATE

\footnotetext{
${ }^{25}$ Future researches for the case of Sudan could consider the Murabahah profit margin as a proxy for the opportunity cost of holding cash. In addition, substitution between cash and assets may operate differently in Sudan due to the limited availability of interest-bearing financial assets. Future researches could also discuss the best proxy for quarterly GDP in the absence of industrial production index.

${ }^{26}$ This weighted average includes the operations of the $\mathrm{BCB}$ in the repo market.
} 
shows an increase of the growth rate of the CIC before it starts decreasing. The impulse responses also suggest that the growth rate of the CIC increases with GDP growth (Figure 4). However, the coefficients associated with the policy rate lags in the equation where the CIC_YOY is the dependent variable are not statistically significant.

Figure 3. Banco Central do Brasil Policy Rate (2000-16)

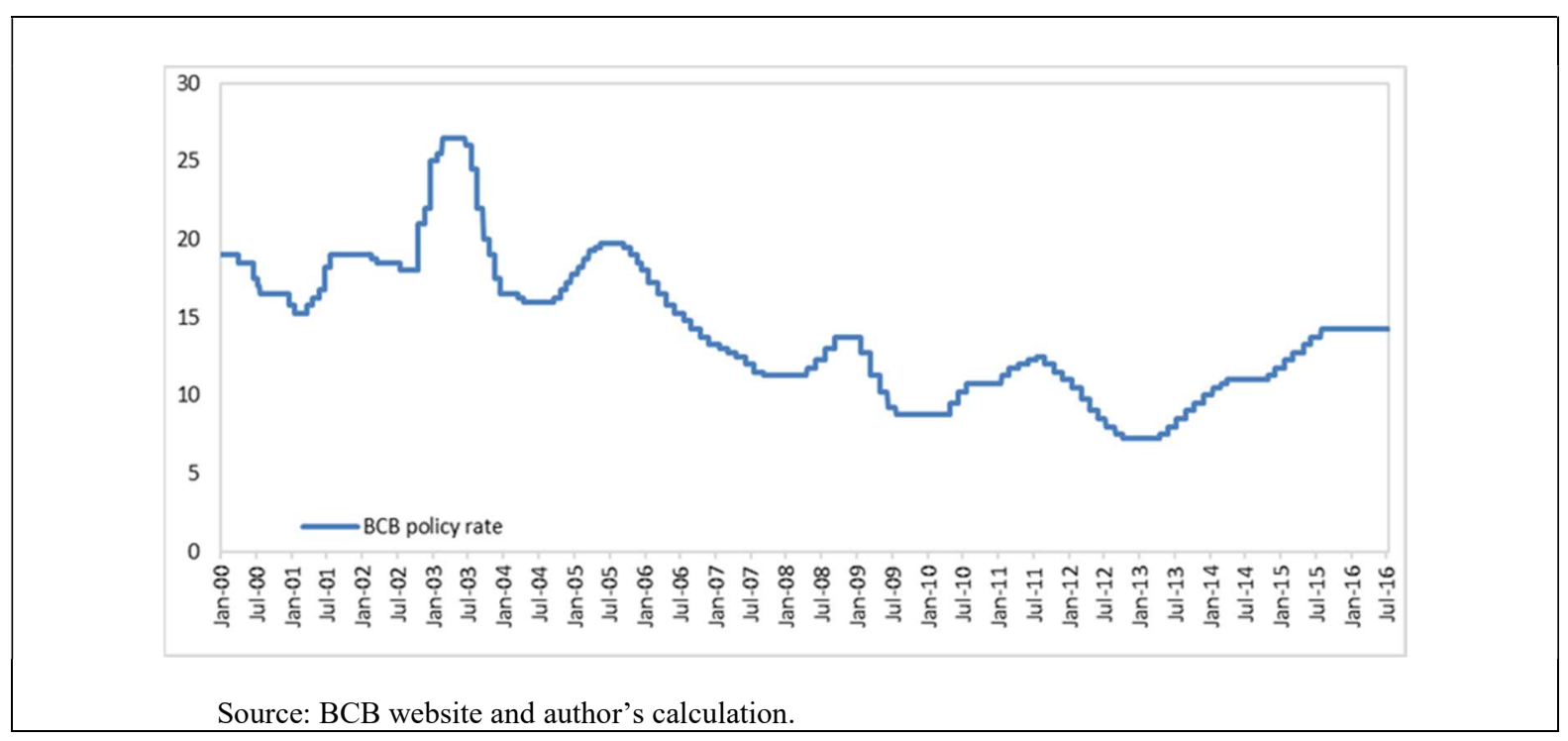

Figure 4. Brazil-Reaction of the Currency in Circulation to the Policy Rate

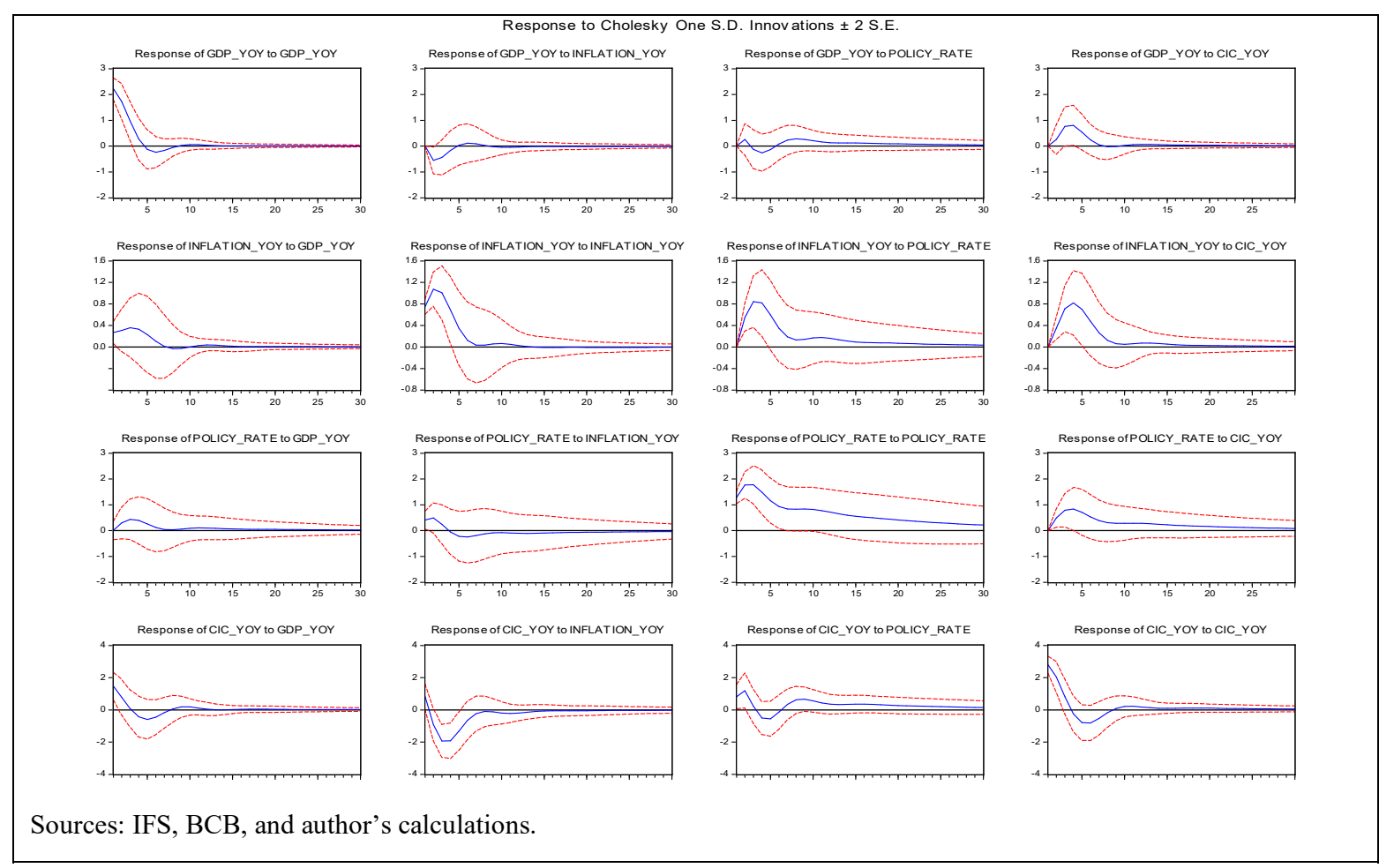




\section{B. Kazakhstan}

The National Bank of Kazakhstan (NBK) has maintained a stabilized exchange rate against the US dollar during several years. However, following several exogenous shocks, ${ }^{27}$ the NBK decided that an adjustment of the exchange rate regime and its overall monetary policy framework was desirable. As a first step, on July 15, 2015, the NBK widened the exchange rate band and, on August 20, 2015, announced the adoption of a floating exchange rate regime. Shortly after, in early September 2015, the NBK introduced a new operational framework composed of a new policy rate, the base rate. Before September 2015 the main policy rate of the NBK was the refinance rate, that is, the rate of its main refinancing operations. In February 2016, the NBK resumed the practice of using the base rate - that was suspended earlier - as the main tool of monetary policy. In order to meet the balance of risks, the base rate was set at 17 percent. When financial markets conditions started stabilizing and forecasts of macroeconomic indicators improving, the NBK started gradually lowering the base rate. In 2017, the base rate was decreased from 12 to 10.25 percent within a $+/-100$ basis point corridor width.

In order to maintain the Tenge Overnight Index Average (TONIA) ${ }^{28}$ within the newly established corridor system, the NBK uses several liquidity injection and absorption instruments. The NBK operational framework comprises a standing credit facility (the Kazakhstan Stock Exchange [KASE] reverse repo from the NBK perspective), and a liquidity-providing OMO auction with a seven-day maturity (purchase of securities with reverse sale). In terms of liquidity-absorbing instruments, the NBK issues its own notes as main sterilization instruments in times of excess liquidity, but also makes use of seven-day deposits and overnight uncollateralized deposits as well as the KASE direct repo (Figure 5).

To explore the currency demand-interest rate relation in Kazakhstan, we estimated the same VAR including four endogenous variables: the yoy GDP growth (GDP_YOY), the yoy inflation (INFLATION_YOY), the policy rate (POLICY_RATE), and the yoy growth rate of the CIC (CIC_YOY). Over the estimation period, 2004:Q4-2015:Q1, the NBK refinance rate is used as the main policy rate. The introduction of the base rate in September 2015 does not provide sufficient data to assess its impact on the CIC. The impulse responses show no significant response of the growth rate of the CIC to an increase in the POLICY_RATE: the result is not unexpected since the refinance rate was targeted to other objectives than monetary policy. ${ }^{29}$ The impulse responses also suggest that the growth rate of the CIC increases with GDP growth and decreases with inflation (Figure 6). Since the Engel-Granger tests indicate that the series included in the VAR are rather co-integrated, we also estimate a

\footnotetext{
${ }^{27}$ These shocks included the oil price slump, the depreciation of the Russian ruble, and the slowdown in China.

${ }^{28}$ TONIA is the weighted average interest rate on one business day repo opening deals concluded on KASE.

${ }^{29}$ Since the NBK refinance rate was not reflective of monetary conditions during the period considered, other indicators, such as the nominal exchange rate could be tested in future researches.
} 
Vector Error Correction Model (VECM) with the same variables: the impulse responses of the VECM display similar results than the VAR, that is, no significant response of the growth rate of the CIC to an increase in the POLICY RATE.

Figure 5. National Bank of Kazakhstan Introduction of Corridor System (2015-17)

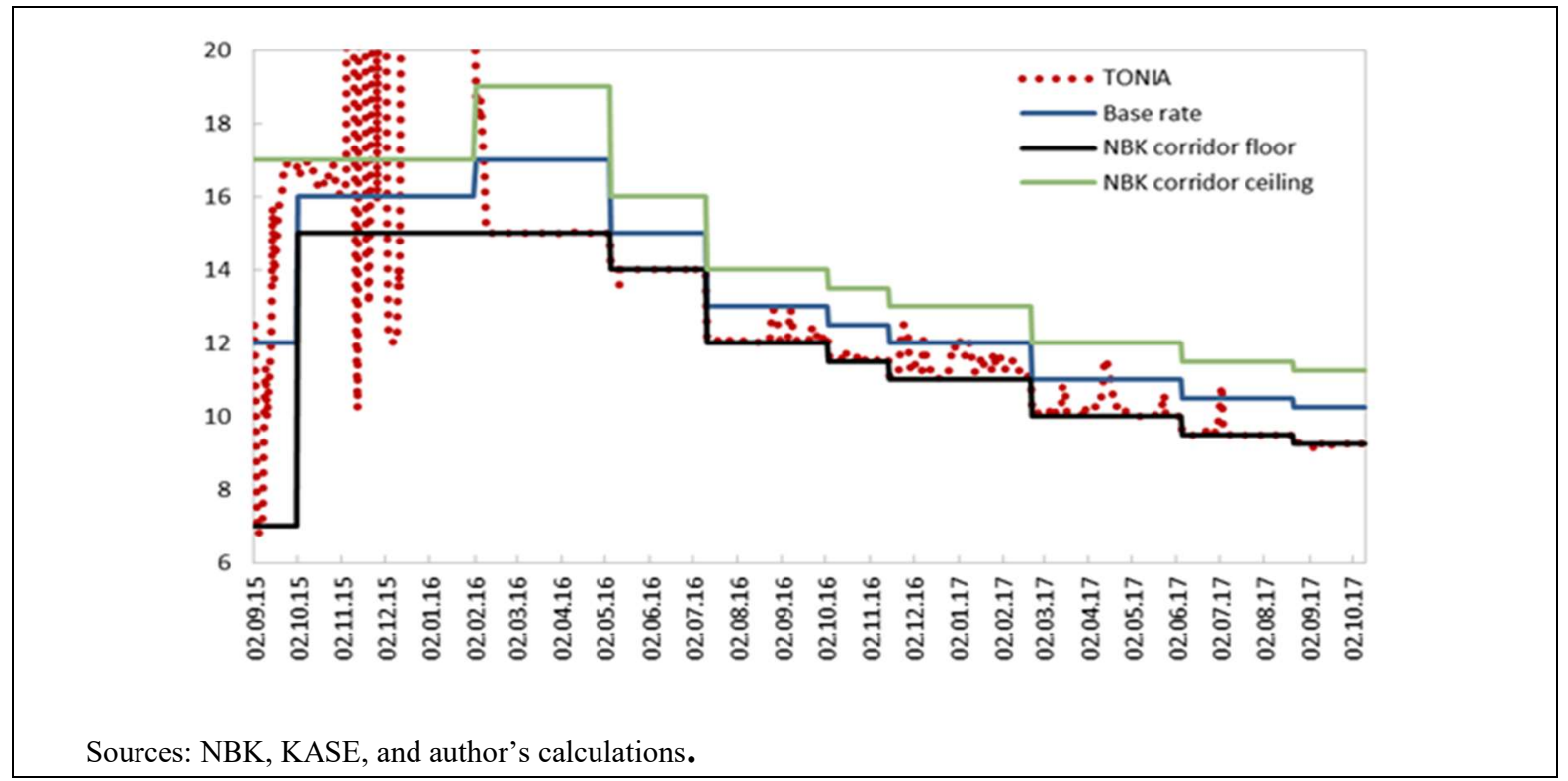

Figure 6. Kazakhstan-Reaction of the Currency in Circulation to the Policy Rate
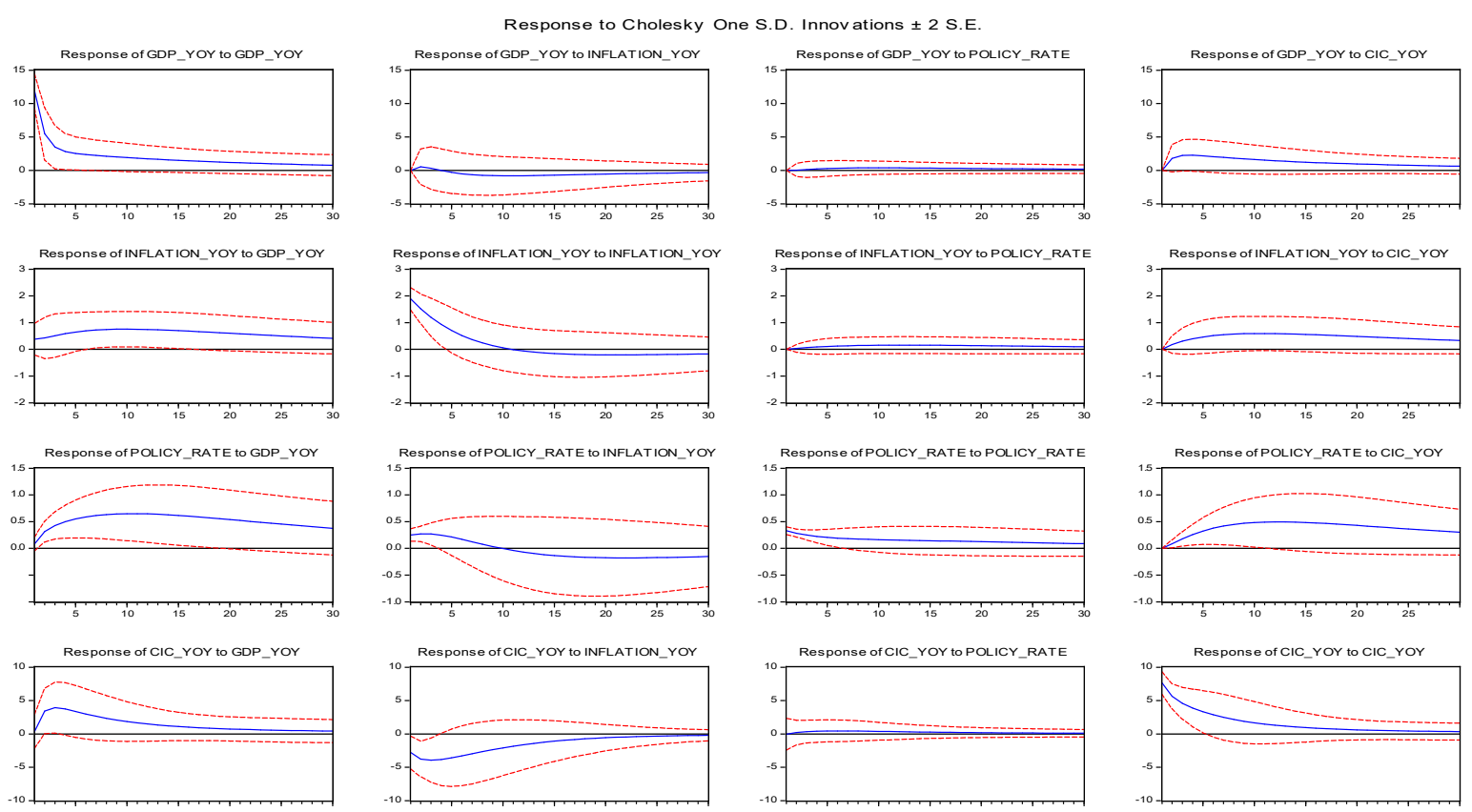

Sources: IFS, NBK, and author's calculations. 


\section{Morocco}

Since 1973 Morocco has maintained a fixed exchange rate against a basket of currencies, reflecting the structure of Morocco's foreign trade. Since April 2015 the foreign currency weights of the Moroccan dirham currency basket have been 60 percent EUR and 40 percent USD. The composition and weights of the basket as well as the bands around the central parity are transparent and disclosed by Bank Al-Maghrib's (BAM). The currency basket allowed Morocco to enjoy several years of low and stable inflation and BAM to fulfill its price stability mandate while preparing for a move to further exchange rate flexibility.

According to Article 6 of its Law, BAM's monetary policy objective is to ensure price stability. The Board of BAM meets quarterly to make monetary policy decisions. The Board sets BAM's main policy rate as well as the reserve requirement (RR) ratio and remuneration. Monetary policy decisions made by the Board are publicly communicated in a quarterly statement released after each meeting, and explained in a quarterly Monetary Policy Report. BAM's Board is composed of the Governor (chairman), the general manager of the central bank, the head of the Treasury Department, and six members appointed by the Prime Minister, three on the Governor's proposal. The head of the Treasury Department does not take part in monetary policy votes. ${ }^{30}$

In this context, BAM has successfully operated a corridor system since 2007 (Figure 7). BAM's corridor system aims to maintain the overnight transaction-based uncollateralized interbank market rate (weighted average) within a $+/-100$ basis points interest rate corridor. To achieve this objective, BAM uses mainly its seven-day liquidity-providing OMOs conducted as repo operations, as well as overnight standing credit and deposit facilities. BAM's operational framework also includes a full range of structural, long-term, and finetuning operations that are occasionally used when needed.

To explore the currency demand-interest rate relation in Morocco, we estimated the VAR including four endogenous variables: the yoy GDP growth (GDP_YOY), the yoy inflation (INFLATION_YOY), the policy rate (POLICY_RATE), and the yoy growth rate of the CIC (CIC_YOY). The estimation period is 2002:Q4-2015:Q1. The impulse responses show no significant reaction of the growth rate of the CIC to a policy rate increase (Figure 8).

\footnotetext{
${ }^{30}$ BAM website.
} 
Figure 7. Bank Al-Maghrib Corridor System and Interbank Rate (2007-16)

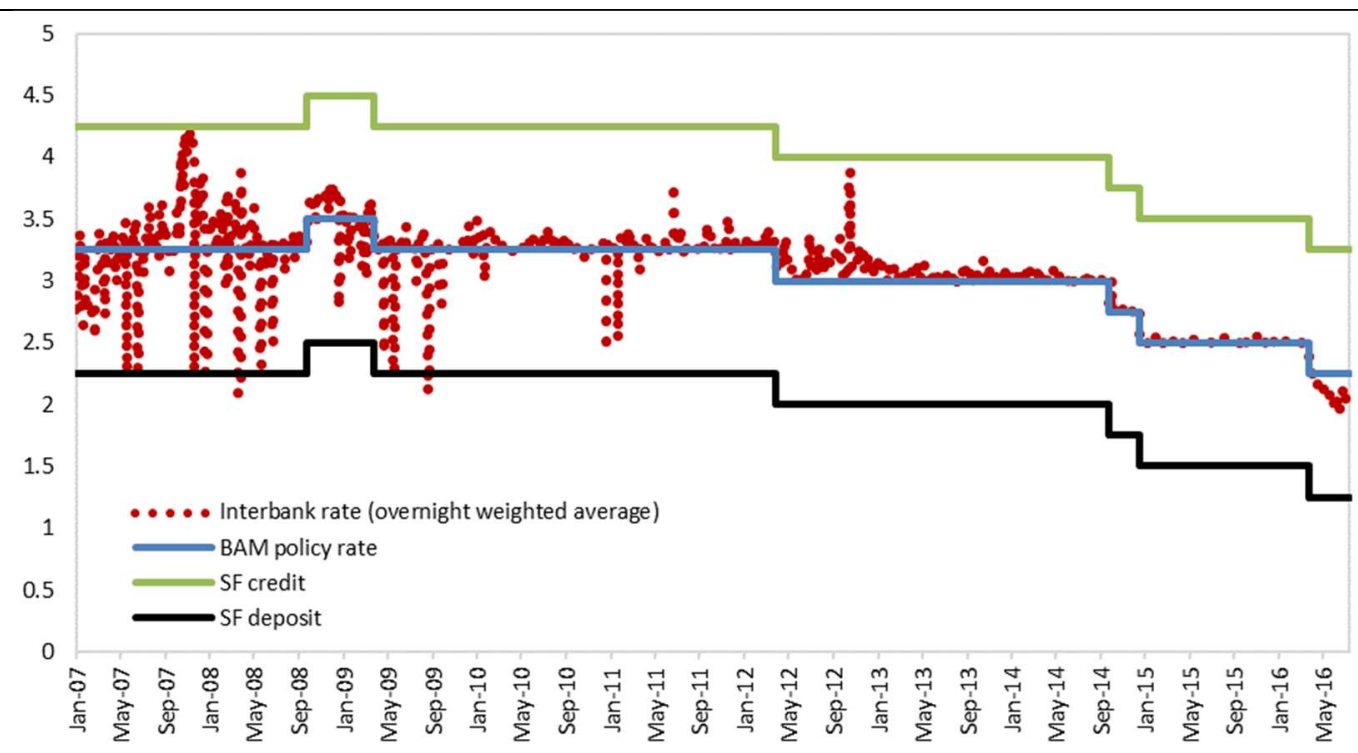

Source: BAM website and author's calculations

Figure 8. Morocco-Reaction of the Currency in Circulation to the Policy Rate

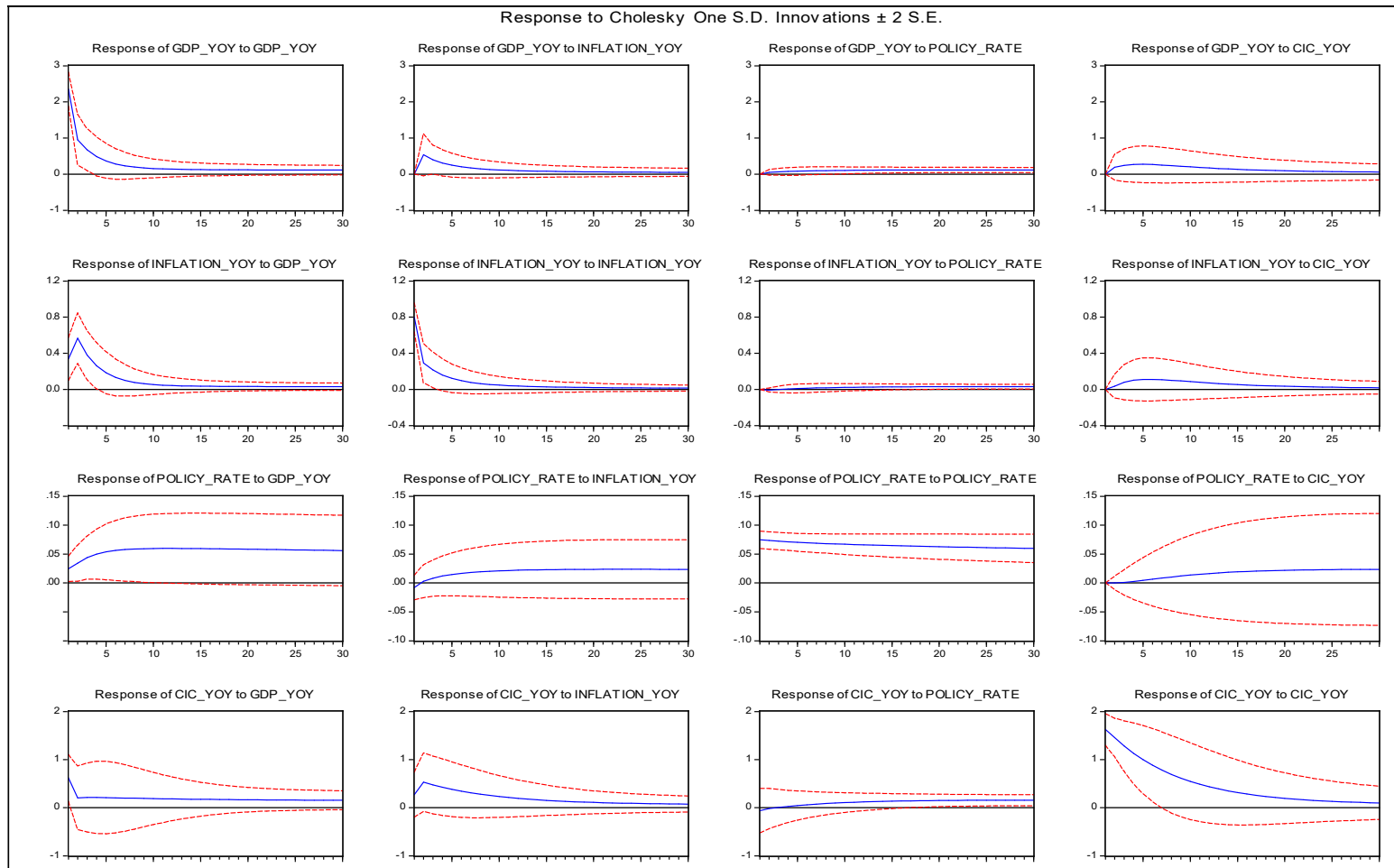

Sources: IFS, BAM website, and author's calculations. 


\section{New Zealand}

By targeting a specific band for inflation, in 1989-90 New Zealand pioneered a new monetary policy regime: inflation targeting (IT). Since then, a number of central banks have adopted IT including those of Brazil, Canada, the UK, Norway, Poland, South Africa, Sweden, and Australia. The Reverse Bank of New Zealand (RBNZ) was given statutory authority to control inflation, provided for in Section 8 of its Act of 1989. The specifics were set out in a contract between the Governor of the RBNZ and the Minister of Finance, signed in 1990. This Policy Targets Agreement (PTA) initially called for a reduction of inflation to a 0-2 percent increase in the consumer price index (CPI) by 1992. A new PTA must be signed each time a Governor is appointed or reappointed, but a new PTA can also be written at other times. Since 1990 there have been a number of PTAs, and the target band has been revised several times as circumstances have changed. According to the RBNZ Act of 1989, the government has the power to override the PTA for a 12-month period. However, any override must be done publicly and transparently. ${ }^{31}$ The current PTA, signed in September 2012, defines price stability as annual increases in the CPI of between 1-3 percent on average over the medium term, with a focus on keeping future average inflation near the 2 percent target midpoint.

Since March 1999 the RBNZ has implemented monetary policy by setting the official cash rate (OCR). The OCR is reviewed seven times a year by the RBNZ. Unscheduled adjustments to the OCR may occur at other times in response to unexpected developments. By setting the OCR, the RBNZ is able to influence the wholesale price of money and, via the linkages to the banking system and financial markets, influence a range of economic factors that help keep inflation under control.

Currently, the RBNZ operates a floor system where the OCR, the key policy rate, is the rate associated to the overnight standing deposit facility (compared to OCR-25 basis points previously). In 2006, the RBNZ moved to a fully cashed-up payment system where the settlement cash level is set by the central bank from time to time. The level is driven by the desire to have short-term interest rates trading close to the OCR and the medium-term demand revealed by payment system participants. This new system was introduced with a target for bank reserves of New Zealand dollar (NZD) 7 billion, and currently reserves sit around NZD 7.6 billion. At the same time as the 2006 introduction of the new operational framework, the RBNZ increased the rate of its overnight standing credit facilities to the $\mathrm{OCR}+50$ basis points (compared to $\mathrm{OCR}+25$ basis points previously). The RBNZ also discontinued its intra-day liquidity facility at that time. The RBNZ predominantly uses FX swaps to manage the level of reserves in the banking system and also holds OMOs, as and

${ }^{31}$ RBNZ (2007). 
when required, using RB bills and repurchase transactions. Since 2008, the RBNZ has accepted a wide range of acceptable securities for its repurchase transactions (Figure 9). ${ }^{32}$

VAR estimations for New Zealand over the period 2000:Q2-2013:Q4 and impulse responses show a decrease of the growth rate of the CIC over five quarters following a monetary policy shock. However, the coefficient associated with the policy rate lag in the equation where the CIC_YOY is the dependent variable is not statistically significant. The impulse response also suggests that the growth rate of the CIC increases with GDP growth (Figure 10).

Figure 9. Reserve Bank of New Zealand Official Cash Rate and Selected Wholesale Funding Rates (2006-16)

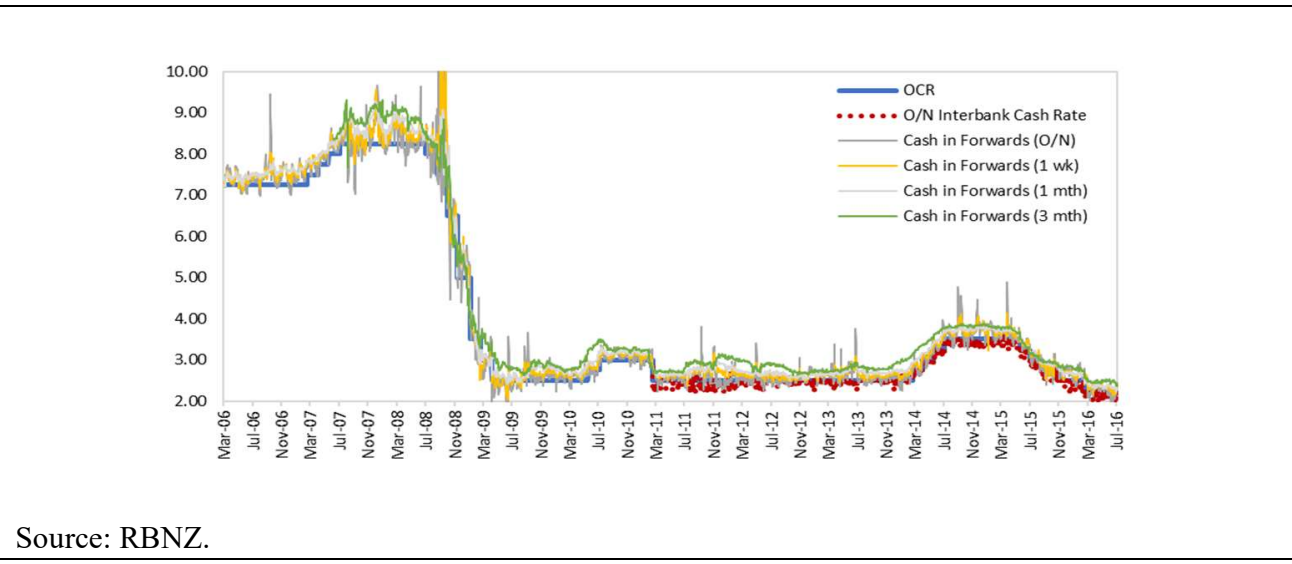

Figure 10. New Zealand-Reaction of the Currency in Circulation to the Policy Rate

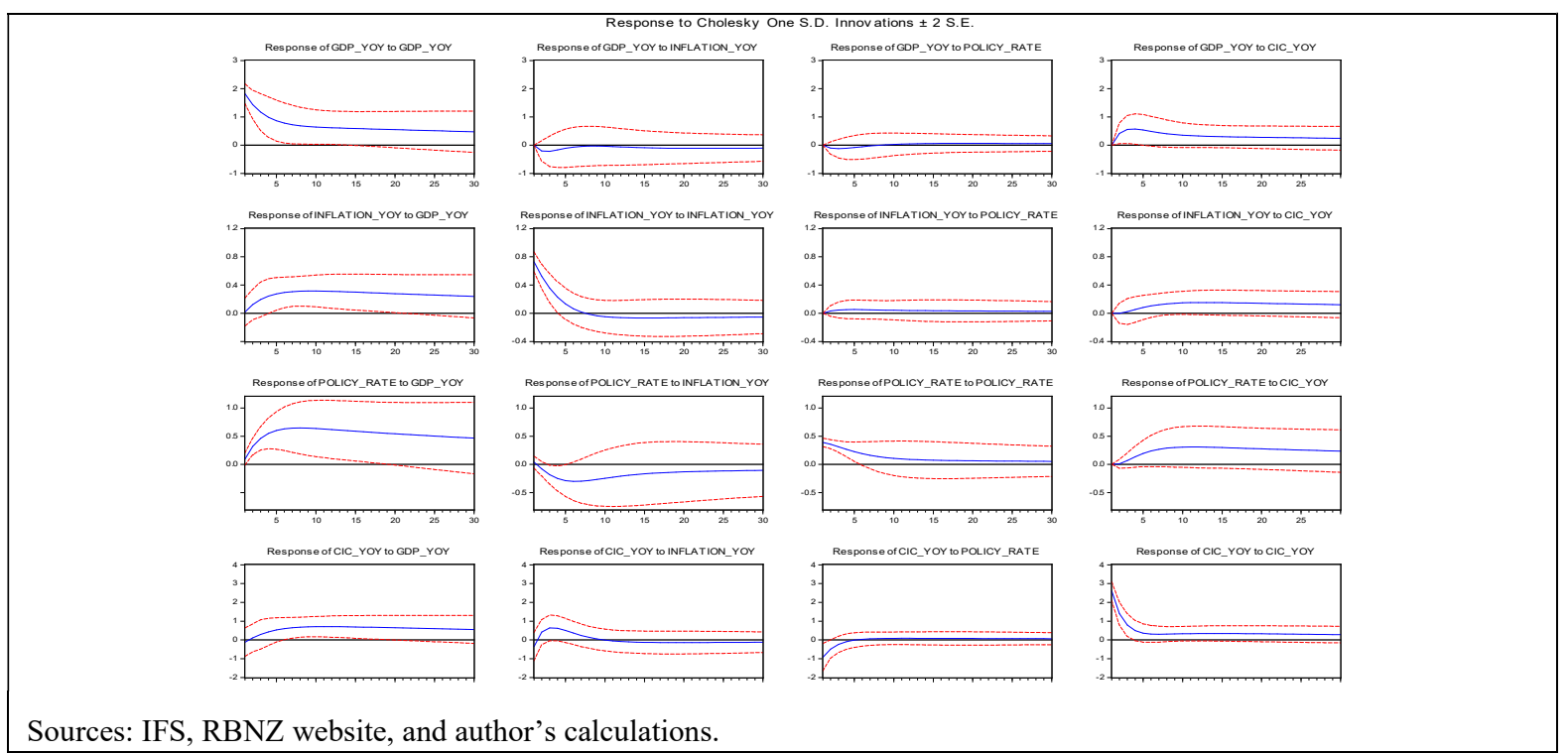

${ }^{32}$ Nield (2006). 


\section{Modeling the Daily Currency in Circulation: Country Cases}

Central banks conduct short-term liquidity forecasts whether their operating target is an interest rate, an exchange rate, or a quantity of money. In particular, accurate liquidity forecasting is a cornerstone of the process of monetary policy transition to an interest ratebased monetary policy, because it replaces quantitative targets by an active calibration of central bank monetary operations based on autonomous factor forecasts. Moving to a calibration of central bank monetary operations based on liquidity forecasts usually means targeting an aggregated banking system excess liquidity — above the reserve requirement (RR) - as low as possible on average over the reserve maintenance period on a forwardlooking basis.

Upgrading central bank liquidity forecasting and operational frameworks should start earlier than the official adoption of an interest rate-based monetary policy. Stabilizing short-term fluctuations of money market rates is an operational fine-tuning process that is usually separated from setting or changing the level of the policy rate. In countries with fixed exchange rate regimes, money is primarily endogenous, and the central bank can lose part of its control over the size of its balance sheet and the growth of the monetary base - but it can still control the size of excess liquidity left in the banking system above the RRs. It can also decide to fully sterilize the surplus liquidity and offset the short-term fluctuations of autonomous factors. Money market rates move close to the policy rate when the market for bank reserves is balanced over the reserve maintenance period. The demand for banks' reserves is primarily linked to banks' need to meet their RR; but banks may also want to hold additional precautionary reserves over the minimum requirement. Large excess reserves held beyond the RR can put downward pressure on money market rates, while an insufficient level of reserves causes interest rates to rise.

Changes in bank reserves are directly derived from autonomous factors' forecasts, using the balance sheet of the central bank. Trends and forecasts of autonomous factors are country specific, in particular with regard to the extent to which NFA fluctuations and government operations affect bank reserves. In economies with flexible exchange rates, central bank FX operations usually do not cause important changes in bank reserves; however, large NFA fluctuations and FX interventions may cause important fluctuations in the SLPB.

Government cash flows can also result in large liquidity shocks and induce higher funding cost volatility whenever government accounts at the central bank fluctuate significantly. Other specific components of the central bank balance sheet can also have a significant liquidity effect, such as stabilization funds, sovereign funds, and oil funds deposits.

Liquidity management requires daily forecasts, typically over the reserve maintenance period. However, liquidity forecasting does not rely only on models and also involves a welldesigned framework including processes, organization, and coordination with the Department of Treasury and market operators. Liquidity forecasting features strong coordination, expert judgment, and market data monitoring components, and necessitates 
centralizing all the necessary information as well as the knowledge and the capacity in a dedicated unit of the central bank. Forecasting errors are common; addressing them needs not only the improvement of the central bank liquidity forecasting framework, but also a welldesigned operational framework including the necessary set of monetary operations. ${ }^{33}$

In this section, we apply the same type of ARIMA modeling with dummy variables as the one used in Cabrero and others (2002) to the daily change of the CIC in five countries: Brazil, Kazakhstan, Morocco, New Zealand, and Sudan. The key findings are the following:

- In the five countries, the CIC displays marked seasonal patterns.

- There is a clear trading day effect on Fridays for Brazil, Kazakhstan, and Morocco, and on Thursdays for New Zealand. This reflects that the CIC increases just before the weekend and decreases after the weekend, at the beginning through the middle of the week (Figures 11 and 12).

- The CIC also increases with salary payments, which occur twice a month in Kazakhstan and New Zealand, and once a month in Brazil, Morocco, and Sudan (intra-monthly seasonality).

- Finally, the CIC rises during holidays periods and toward the end of the year (intraannual seasonality).

To model the effect of the trading day, the intra-monthly behavior of the CIC related to payroll dates, as well as the holiday effects, several dummy variables are constructed and tested for each country following the ARIMA model structure presented in Box 2. These dummy variables are the following:

- Variables related to the intra-weekly seasonality. Five variables have been created to simulate the intra-weekly behavior of the CIC. These variables are Monday, Tuesday, Wednesday, Thursday, and Friday. Each of these variables takes the value of 1 on the correspondent day and 0 otherwise.

- Variables related to the intra-monthly seasonality. Four variables, that is, Week1, Week2, Week3, and Week4, are generated to take into account the patterns of the CIC, which usually increases during the first two weeks of the month and decreases in the second half of the month.

- Variables related to the intra-yearly seasonality. Two sets of dummy variables are used to simulate the intra-yearly behavior of the CIC. The first set includes $k$

\footnotetext{
${ }^{33}$ See Appendix I for further details on liquidity forecasting.
} 
variables, $W 1, \ldots, W k, k$ being the number of weeks in the year. The second set of variables are $M 1, \ldots, M 12$, each one taking the value of 1 during the corresponding month of the year and 0 otherwise.

- Holiday dummy variables. The dummy variable $H$ takes the value of 1 on the dates corresponding to the country's holidays and 0 otherwise. Further, to take into account the fact that a holiday has a different effect on the CIC when it is a Monday, a Tuesday, a Wednesday, a Thursday, or a Friday, several other dummies have been generated. These variables are: $M 1, \ldots, M i$ when the holiday is a Monday; $T 1, \ldots, T j$ when the holiday is a Tuesday; Wedl,..., Wedk when the holiday is a Wednesday; $T h 1, \ldots, T h l$ when the holiday is a Thursday; and $F 1, \ldots, F m$ when the holiday is a Friday.

- Salary variables. The dummy variable $S$ as well as its lags and future values simulate the effect of payroll dates on the CIC. $S$ takes the value 1 when salaries are paid at the corresponding day and 0 otherwise.

In addition to these dummies, specific variables have been created for each country to model significant calendar effects such as those related to Christmas for Brazil and New Zealand, as well as Easter for New Zealand, and Eid Al-Adha and Eid Al-Fitr for Morocco and Sudan. These dummy variables are detailed hereafter in each country's subsection.

The ARIMA model developed for each country is estimated using OLS regression. The dependent variable is the daily change of the CIC that is stationary for the five countries. ${ }^{34}$ CIC is not stationary and displays a trend for the five countries (Appendix III). The identification of the models is based on the significance of the parameters, the autocorrelation function and partial autocorrelation function, as well as the residuals diagnosis. Estimation results display adjusted R-squared that range from a maximum of 0.92 for Brazil and 0.71 for New Zealand, as shown in Table 1. However, the CIC model for New Zealand does not include the salary payment dummy, while in Brazil, the salary dummy and its past and future values are statistically significant.

Table 1. Currency in Circulation Models-R-Squared and Adjusted R-Squared

\begin{tabular}{l|cc}
\hline & R-squared & Adjusted R-squared \\
\hline Brazil & 0.927939 & 0.919730 \\
Sudan & 0.874755 & 0.862072 \\
Morocco & 0.805276 & 0.799527 \\
Kazakhstan & 0.748668 & 0.741218 \\
New Zealand & 0.726685 & 0.713336 \\
\hline
\end{tabular}

${ }^{34}$ Augmented Dickey-Fuller tests have been applied to test for the stationarity of the daily change of the CIC. 
Figure 11. Trading Day Effect

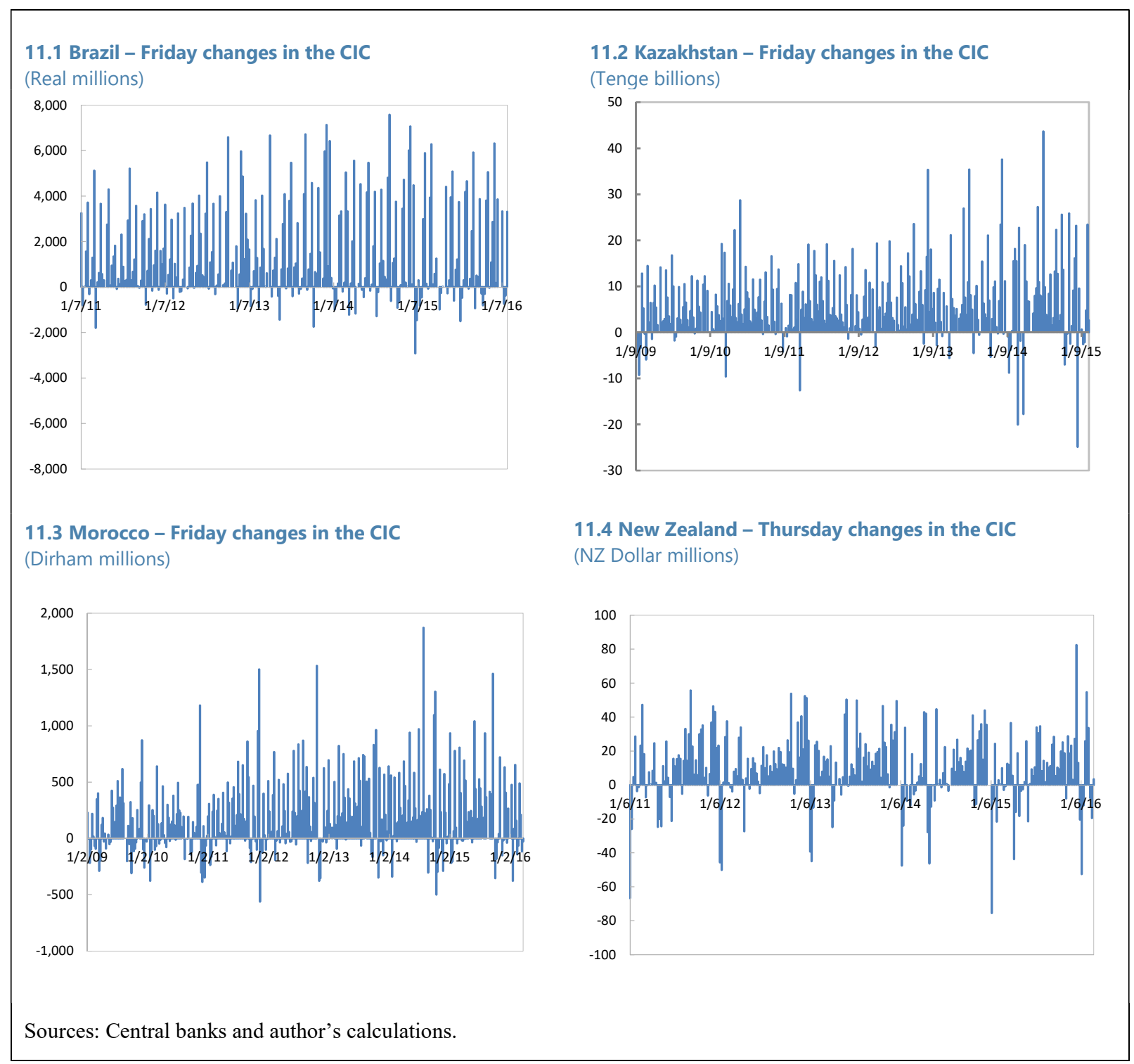


Figure 12. Beginning to Midweek Decrease in the Currency in Circulation

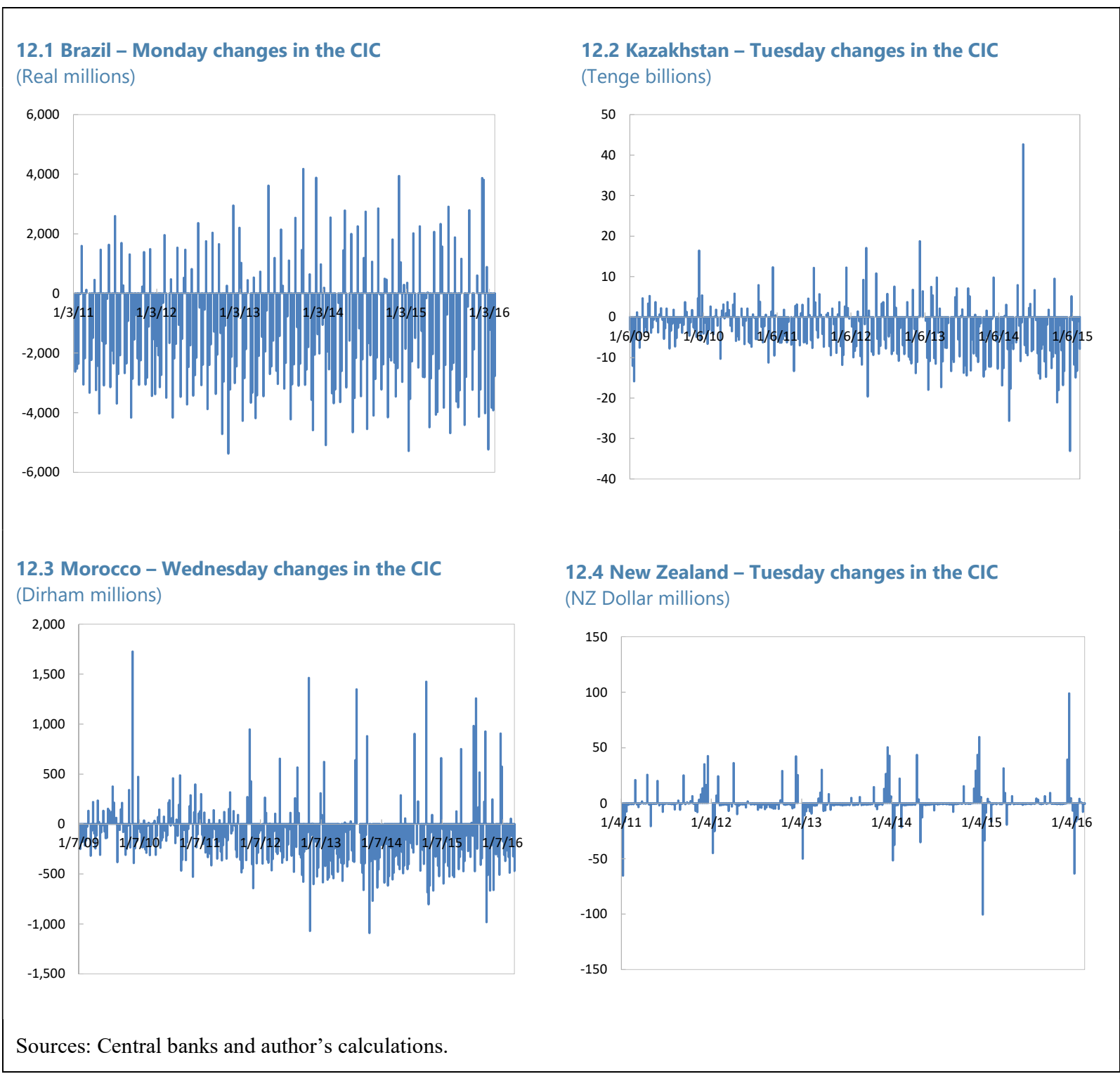

\section{A. Brazil}

In Brazil, the CIC displays a similar profile each year, as shown in Figure 13, with marked increases at the beginning of each month. This replicable profile over months and years, as well as the persistent effect of payrolls, resulted in the highest adjusted R-squared obtained among the five countries considered. In Brazil, salaries are usually paid in the first days of each month, up to the fifth day of each month. An important seasonal effect is related to the thirteen salary payment, usually paid in December.

The CIC model for Brazil has been estimated over the period 1/03/2011 to 1/29/2016. The stochastic structure of the model includes 22 AR terms and one MA term, as shown in the regression results (Appendix IV). The deterministic structure of the model includes intra- 
yearly dummy variables, holiday variables, and all the days of the week. Specific dummy variables have also been introduced for Christmas: these variables are $C_{-} 1, \ldots, C_{-} 15$ that take into account the increase in the CIC 15 days before Christmas, and $C 1, \ldots, C 15$ that model the decrease of the CIC after Christmas. However, only four of these variables turned out to be significant. In addition, several lags and future values of the salaries variable $S$ have been introduced in the model to account for the persistence of the payroll effect.

Brazil's main national holidays include the Gregorian New Year (January 1), Carnival Day and day after (February), Good Friday (March), Tiradentes Day (April), Labor Day (May 1), Corpus Christi (May-June), Independence Day (September 7), Our Lady Aparecida (October 12), All Souls' Day (November 2), Republic Proclamation Day (November 15), and Christmas Day (December 25). The most important calendar effect is the cumulated effect of Christmas and New Year, which coincides with the payment of the thirteen salary. During this period, the CIC increases substantially (Figure 13).

\section{Figure 13. Currency in Circulation in Brazil and New Zealand during Christmas and New Year}

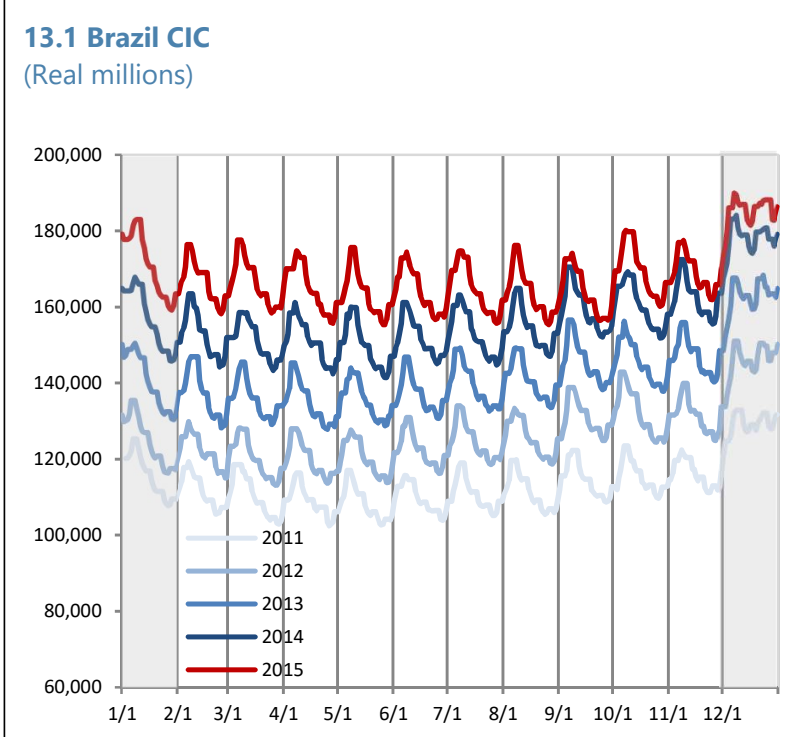

13.2 New Zealand CIC
(NZ Dollar millions)

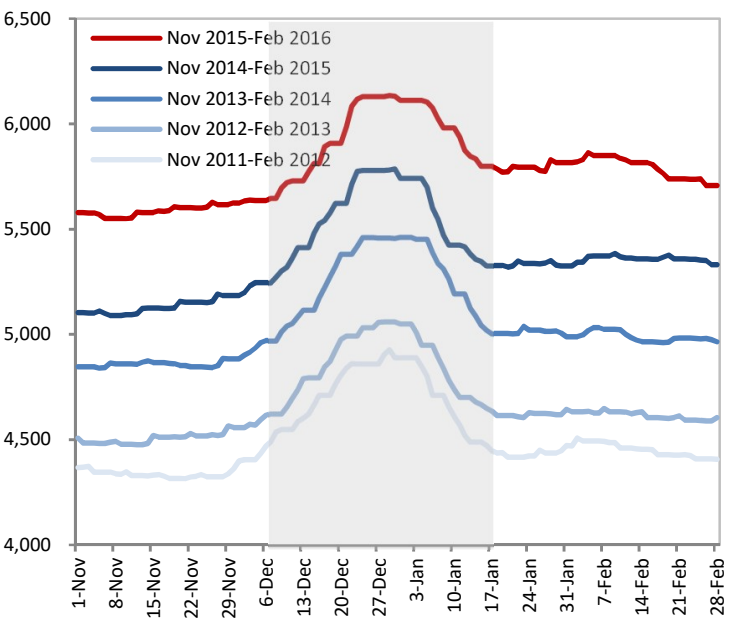

Sources: Central banks and author's calculations.

\section{B. Kazakhstan}

The ARIMA model for Kazakhstan has been estimated over the period 1/03/2011 to $12 / 31 / 2014$. The stochastic structure of the CIC model includes 13 AR terms and one MA term, as shown in the regression results (Appendix V). The deterministic structure of the model includes intra-yearly dummy variables, holiday variables, and the trading day effect, FRIDAY, that turned out to be statistically significant, as well as the salary dummy variable. 
Kazakhstan's main holidays include the Gregorian New Year (January 1), the Eastern Orthodox Christmas (January 7), Nowruz, the Persian New Year (March), Kazakhstan People's Unity Day (May 1), Defender of the Fatherland Day (May 7), Great Patriotic War Against Fascism Victory Day (May 9), Capital City Day (July 6), Constitution Day (August 30), Eid Al-Adha, First President Day (December 1), and Independence Day (December 16). Eid Al-Adha occurs the tenth day of Dul-Hijja month following the Muslim calendar; on the Gregorian calendar, the dates vary from year to year, drifting approximately 13 days earlier each year (Figure 14).

Figure 14. Kazakhstan Currency in Circulation Intra-Yearly Seasonality

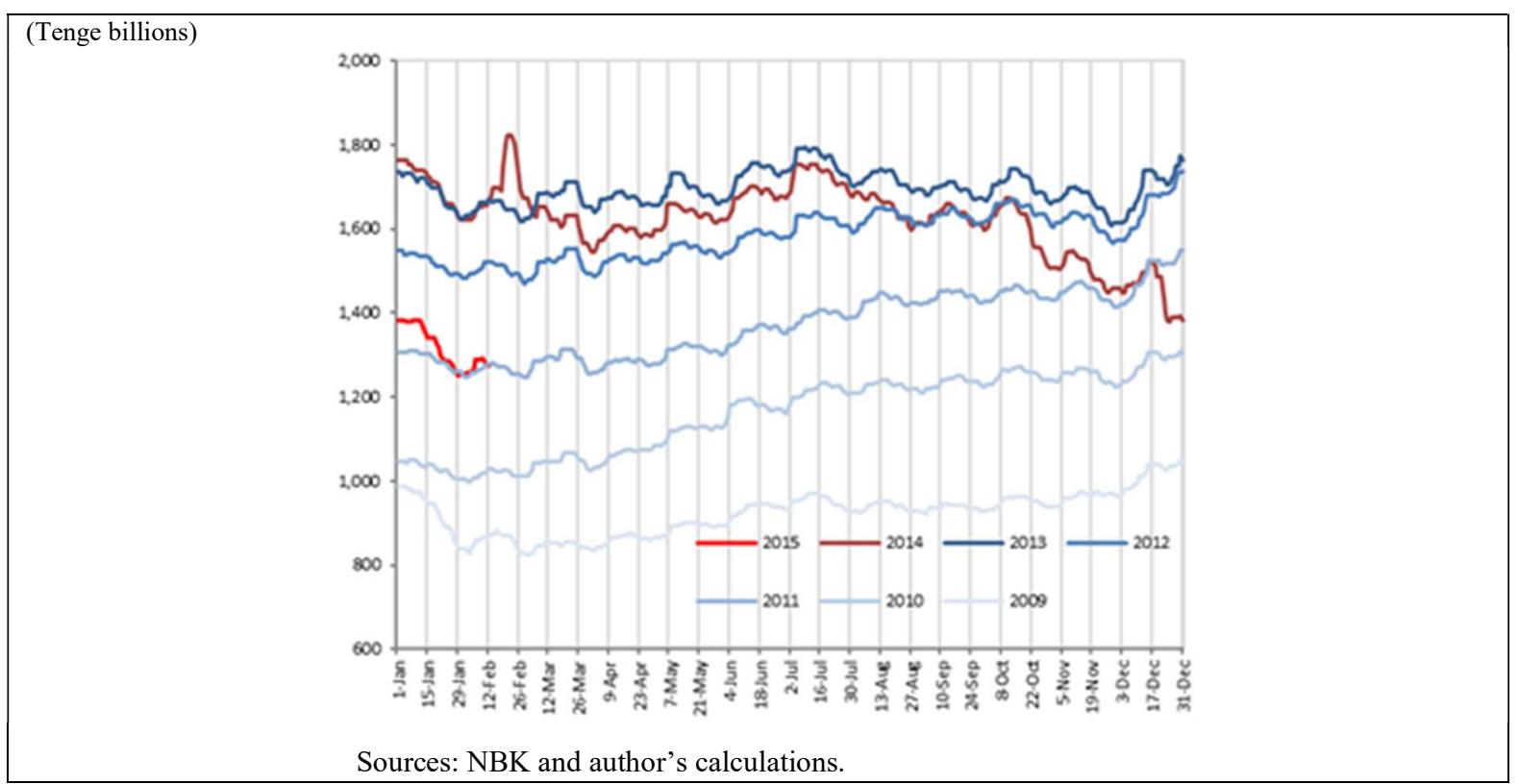

\section{Morocco}

Since 2007 Morocco has used an ARIMA model with dummy variables to forecast the daily changes in the CIC in the context of BAM liquidity management. For the purpose of homogeneity with the other country cases considered in this paper, the ARIMA model for Morocco is estimated over the period 1/03/2011 to 3/21/2016. The stochastic structure of the $\mathrm{CIC}$ model includes four AR terms and one MA term, as shown in the regression results. The deterministic structure of the model includes the holiday dummy variable $H$, the salary payment dummies $S$ and $S 1$, the intra-yearly dummy variables, the trading day FRIDAY, as well as the effects of MONDAY and WEDNESDAY, which are statistically significant. Specific dummy variables have also been introduced to account for the effects of the two major Muslim religious holidays, Eid Al-Adha and Eid Al-Fitr. The dummy variables related to Eid Al-Adha are: $A A_{-} 1, \ldots, A A_{-} 10$ that take into account the increase in the CIC 10 days before Eid Al-Adha, and $A A 1, \ldots, A A 10$ that model the decrease of the CIC after Eid Al- 
Adha. Four dummies, $A F 1, \ldots, A F 4$, have been included to simulate the CIC increase during Eid Al-Fitr (Appendix VI).

Morocco's main holidays include the Gregorian New Year (January 1), Anniversary of the Independence Manifesto (January 11), Labor Day (May 1), Feast of Throne (July 30), Recovery Oued Ed-Dahab (August 14), Revolution of the King and the People (August 20), Youth Day (August 21), Green March (November 6), and Independence Day (November 18). The holidays specific to the Muslim calendar are the Hijra New Year (Muharram, 1 on the Muslim calendar), Eid Al-Mawlid (Rabi'I, 12), Eid Al-Adha (Dul-Hijja, 10), and Eid Al-Fitr (Shawwal, 1). In the Gregorian calendar, the dates vary from year to year, drifting approximately 13 days earlier each year (Figure 15).

Figure 15. Morocco and Sudan Specific Calendar Effects

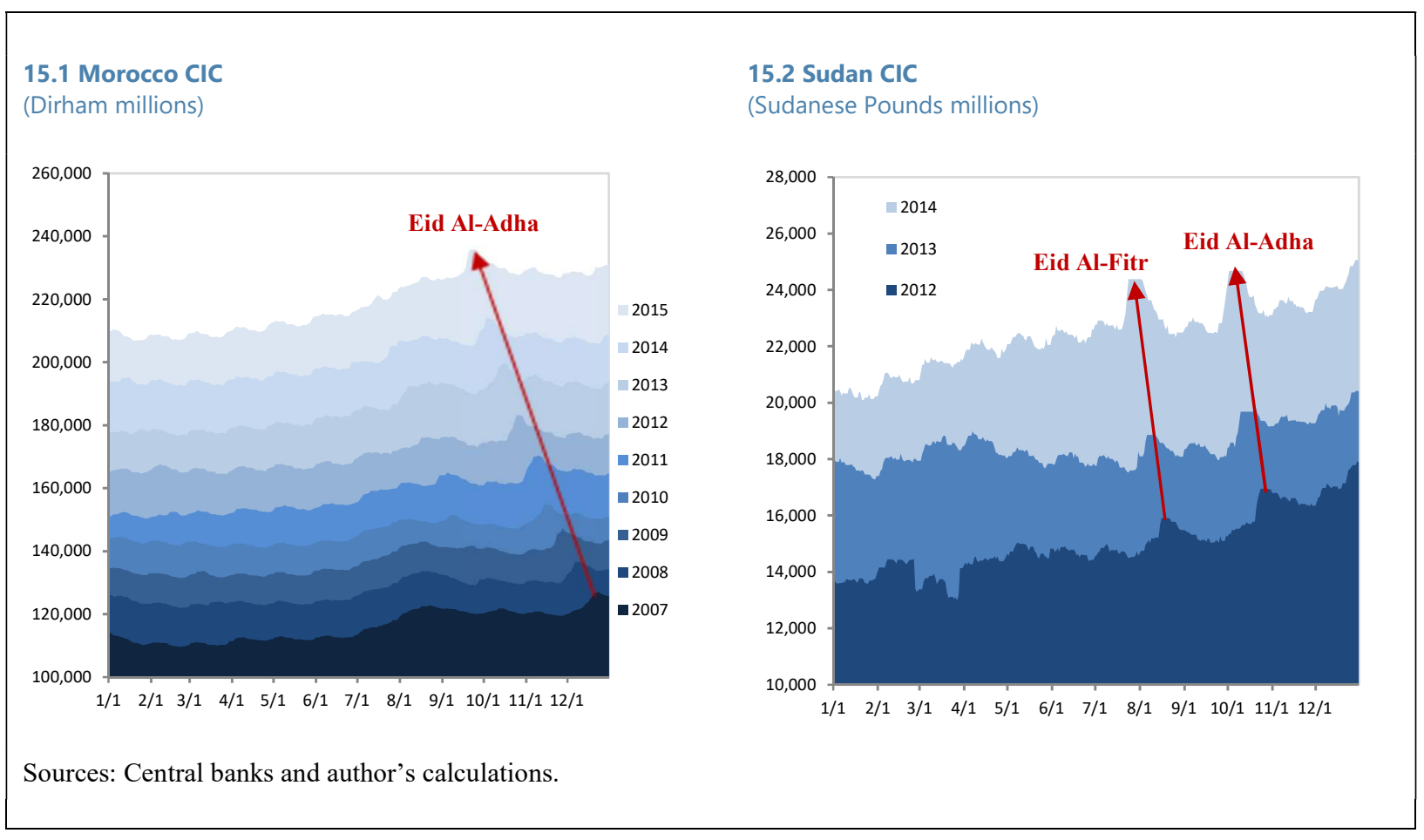

\section{New Zealand}

The CIC model for New Zealand has been estimated over the period 1/03/2011 to 2/29/2016. The stochastic structure of the model includes six AR terms and 10 MA terms, as shown in the regression results (Appendix VII). The deterministic structure of the model includes intra-yearly dummy variables, holiday variables, and all the days of the week except THURSDAY. As for Brazil, specific dummy variables have been introduced for Christmas $\left(C_{-} 1, \ldots, C_{-} 15\right.$ and $\left.C 1, \ldots, C 15\right)$. In addition, specific dummy variables have been also added to model the CIC increase during Easter $\left(\mathrm{E}_{-} 1, \ldots, \mathrm{E}_{-} 10\right.$ and $\left.\mathrm{E} 1, \ldots, \mathrm{E} 10\right)$. 
New Zealand's main national holidays include the Gregorian New Year and the day after (January 1 and 2), Waitangi Day, Good Friday, Easter Monday, ANZAC Day, Queen's Birthday, Labour Day, Christmas, and Boxing Day. The most important calendar effect in New Zealand is the cumulated effect of Christmas and New Year, during which the CIC increases substantially (Figure 13.2 and appendix III).

\section{E. Sudan}

Sudan is an interesting case in the modeling and forecasting of the CIC, as it differs from the other countries both in terms of calendar and behavior of the CIC during holidays. Even though Morocco is a Muslim country where the CIC increases during Eid Al-Fitr and Eil AlAdha, weeks in Morocco start on Monday with weekends on Saturday and Sunday, whereas in Sudan, the week starts on Sunday. In addition, during some Sudan official national holidays, a change in the CIC can be observed. That is not the case in the other four countries considered, where a zero-change in the CIC is usually the standard on official holiday dates. These specific features have not constrained the adaptation of the same type of ARIMA modeling to the CIC in Sudan, the adjusted R-squared of the model for Sudan being 0.86, as shown in Appendix VIII.

The CIC model for Sudan has been estimated over the period 1/01/2012 to 12/31/2014. The stochastic structure of the model includes $22 \mathrm{AR}$ terms and one MA term. The deterministic structure of the model includes intra-yearly dummy variables and holiday variables as well as SUNDAY and WEDNESDAY. Specific dummy variables have also been introduced to account for the effects of the two major Muslim religious holidays, Eid Al-Adha and Eid AlFit. The dummy variable related to Eid Al-Adha are: $A D H A_{-} 1, \ldots, A D H A_{-} 10$ that take into account the increase of the CIC 10 days before Eid Al-Adha, and ADHA1, .., ADHA10 that model the decrease of the CIC after Eid Al-Adha. Four dummies, FITR_1, .., FITR_4, have been included to simulate the CIC increase before Eid Al-Fitr (Appendix VIII). ${ }^{35}$

Sudan's main holidays include Independence Day (January 1), the Coptic Christmas (January 8), the Coptic Easter (May 1), and Revolution Day (June 30). The holidays specific to the Muslim calendar are the Hijra New Year (Muharram 1 on the Muslim calendar), Eid AlMawlid (Rabi'I, 12), Eid Al-Adha (Dul-Hijja, 10), and Eid Al-Fitr (Shawwal, 1). On the Gregorian calendar, the dates vary from year to year, drifting approximately 13 days earlier each year (Figure 10).

\footnotetext{
${ }^{35}$ Further research for Sudan could investigate how to better capture the effects of the two agricultural seasons (June-July and October-November) as well as the riot period of September 2013. The first riot period (July 2005 ) is outside the estimation period (1/01/2012 to 12/31/2014). Currency Change Overs in Sudan (AprilAugust 2007 and July-October 2011) are also outside the estimation period.
} 


\section{CONCLUSION}

The following conclusions can be drawn from our work:

- Long-term versus short-term determinants of the CIC. When considering the determinants of the $\mathrm{CIC}$, a clear distinction between the macroeconomic long-term determinants of the demand for cash and its short-term determinants is needed. Consequently, modeling the CIC over the short run and the longer run necessitates different frameworks and modeling techniques. On the macroeconomic level, income, prices, and interest rates have been identified by the economic theory as the main drivers of the demand for cash. However, our empirical work shows that higher interest rates do not necessarily decrease the relative attractiveness of cash.

- Transmission of monetary policy shocks to CIC demand. Our empirical work shows that the transmission of monetary policy shocks to the currency demand may be different from one country to another, as monetary transmission, more generally, differs from one country to another. Substitution between cash and interest-bearing assets depends on the availability of fixed income assets in the economy, the depth of bonds markets, and more generally the structure of the financial system.

- Impact of non-macroeconomic variables. When analyzing the transmission of central banks policy rate changes to the currency demand, it is also important to acknowledge that other non-macroeconomic variables such as the denomination and banknote boundary and the existence of secure ways of storage for cash, among other factors, may also affect the transmission of policy rate changes to the demand for cash.

- CIC behavior over the short term. While the transmission of monetary policy shocks to the CIC may differ from one country to another, CIC behavior over the short run displays relatively similar patterns under IT or prohibited interest rate environments. The main short-term determinants of currency demand include weekdays, payroll dates, holidays, and calendar effects. Central banks have mainly relied on ARIMA and STS techniques to model and forecast the daily CIC. An application of ARIMA models to the CIC in five countries-Brazil, Kazakhstan, Morocco, New Zealand, and Sudan — provided good performances, suggesting that they can be adapted to the daily change of the CIC under different monetary policy frameworks and macrofinancial environments.

- Benefits of modeling versus expert knowledge. Forecasts derived from ARIMA models are usually found to outperform those based on pure expert knowledge. This suggests that central banks will gain in terms of accuracy of their liquidity forecasting by modeling the CIC. However, statistical models cannot perfectly substitute experts' judgment. 
- Forecasting the CIC over longer horizons. No matter how sophisticated they are, ARIMA models using daily time series are generally not well suited to producing reliable forecasts over horizons longer than a few days; they are typically intended to calibrate central banks' main OMOs. Therefore, since central banks' monetary operations can be undertaken beyond short-term horizons, it is important to retain lower frequency first generation models, as they help not only forecast the SLPB over the longer run, but also quantify the effect of monetary policy shocks and other macroeconomic variables on the currency demand. 


\section{Appendix I. Liquidity Forecasting}

Liquidity forecasting is the process of centralizing all relevant information that determines the future stance of the overall banking system liquidity, in order to calibrate the volume of the central bank liquidity injection or absorption operations. Hence, the main purpose of short-term liquidity forecasts is to create an information set of the projected evolution of autonomous factors that allows the central bank to smooth the future changes in liquidity conditions. Smoothing liquidity fluctuations creates stable liquidity conditions and helps the central bank to steer a benchmark short-term money market rate. These are preconditions of an effective conduct of monetary policy, since they help market participants to clearly distinguish between changes in the monetary policy stance and temporary "noises" in the liquidity conditions. ${ }^{1}$

The SLPB represents the amount of aggregated banking system liquidity (required and free reserves) before any liquidity injection or absorption has been undertaken by the central bank. Liquidity can be derived and forecasted, over the short run or the long run, using the other components of the central bank balance sheet. At a certain point in time, the SLPB is simply equivalent to bank reserves-RRs and excess reserves - minus central bank net liquidity injections. Once the SLPB has been observed or forecasted, the other component used to assess the level of bank liquidity are the RRs that create an additional need for central bank money (Figure 16).

\footnotetext{
${ }^{1}$ Schaechter (2000).
} 
Figure 1. Banking System Liquidity and the Central Bank Balance Sheet

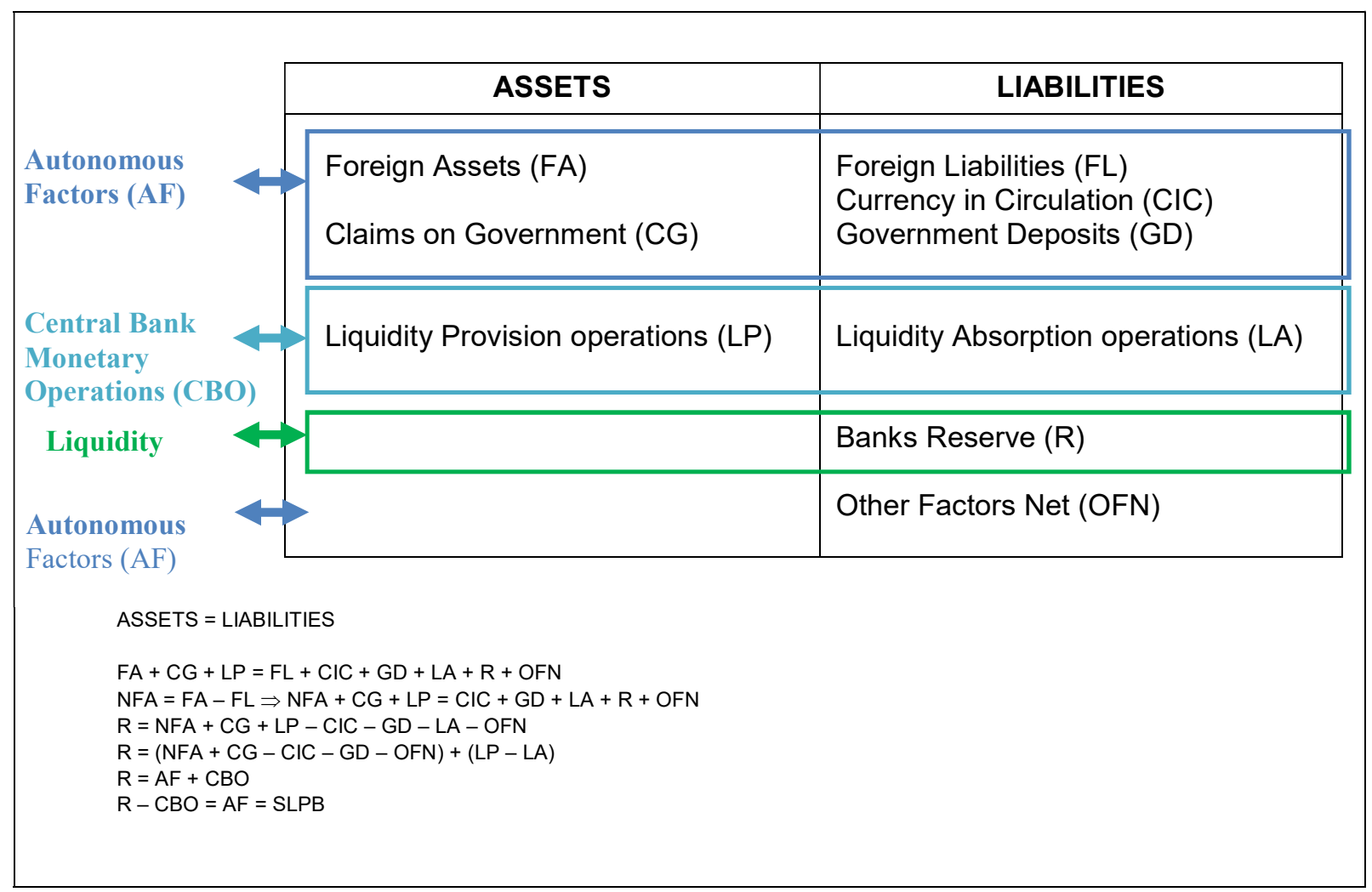




\section{Appendix II. General Structure of the Structural Time Series Model}

$$
\begin{gathered}
y_{t}=\mu_{t}+\gamma_{t}+\psi_{t}+\sum_{i=1}^{m} \eta_{i} O_{i t}+\varepsilon_{t} \\
\mu_{t}=\beta_{t-1}+\mu_{t-1}+\eta_{t} \\
\beta_{t}=\beta_{t-1}+v_{t}
\end{gathered}
$$

Where:

$y_{t} \quad$ is the dependent variable

$\mu_{t} \quad$ is the stochastic trend component of the dependent variable

$\beta_{t} \quad$ is the slope of the trend component

$\gamma_{t} \quad$ is the stochastic seasonal component of the dependent variable. The seasonal component is usually set up in terms of stochastic trigonometric function or in terms of dummy-variable formulation

$\psi_{t} \quad$ is the cycle component

$O_{i t} \quad$ are the dummy variables controlling for the effect of the largest outliers identified

$\varepsilon_{t}, \eta_{t}, v_{t}$ are iid stochastic processes with zero mean and a variance of $\sigma_{\varepsilon}{ }^{2}, \sigma^{2}$ and $\sigma_{v}^{2}$ respectively

\footnotetext{
${ }^{1}$ For further details on STS models, see Cabrero and others (2002), Norat (2008), and Harvey, Koopman, and Riani (1997).
} 


\section{Appendix III. Currency in Circulation-Levels and Daily Changes}

\section{Brazil}

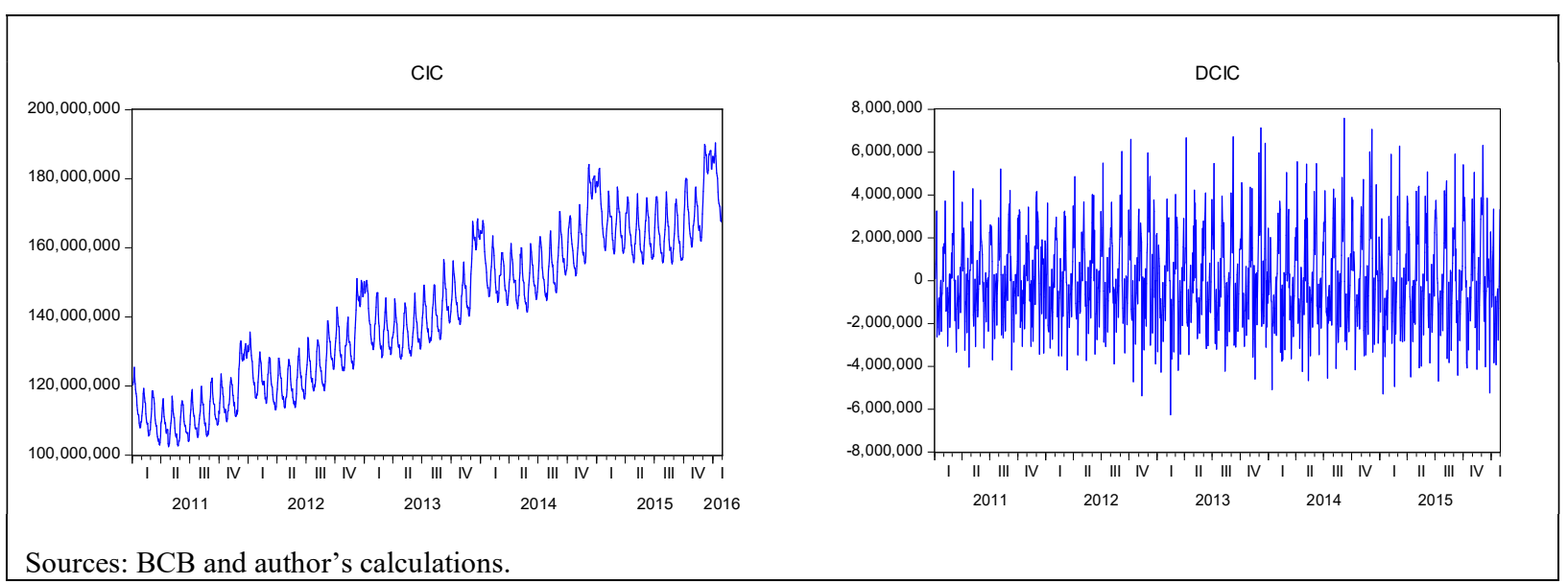

Kazakhstan

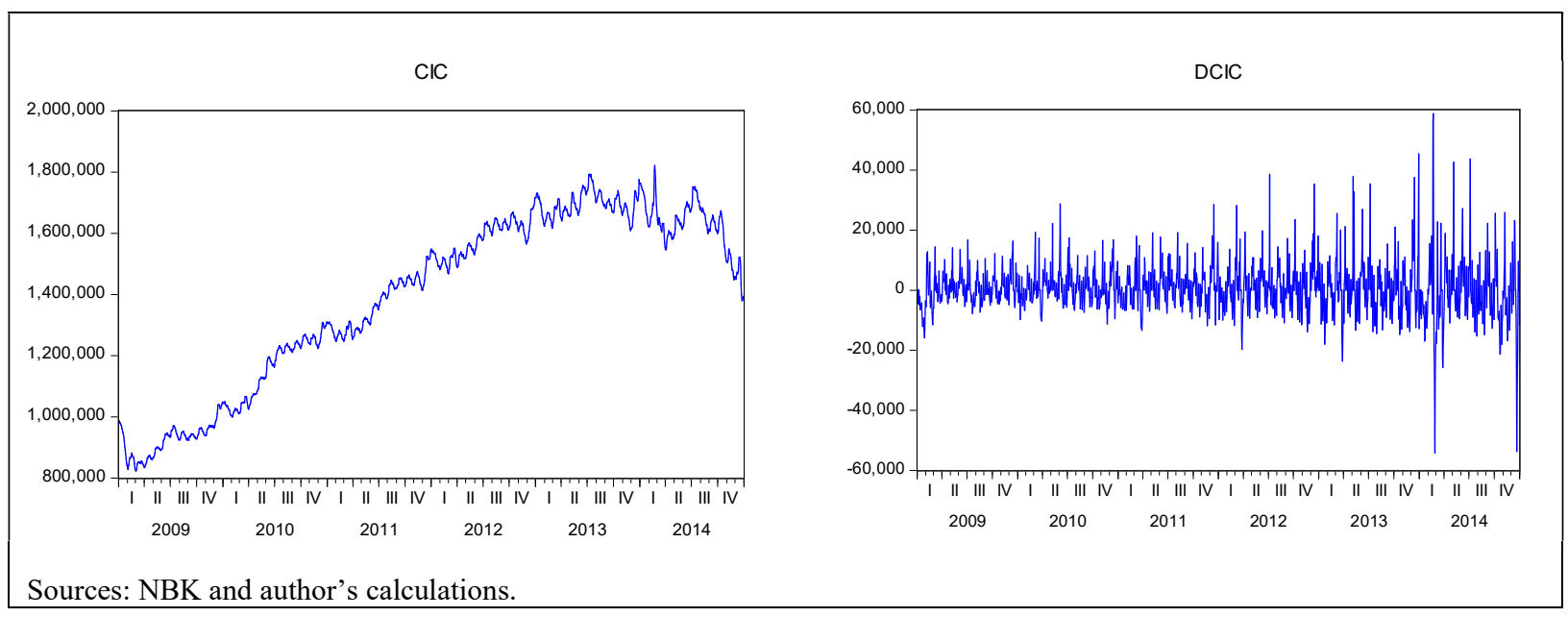

Morocco

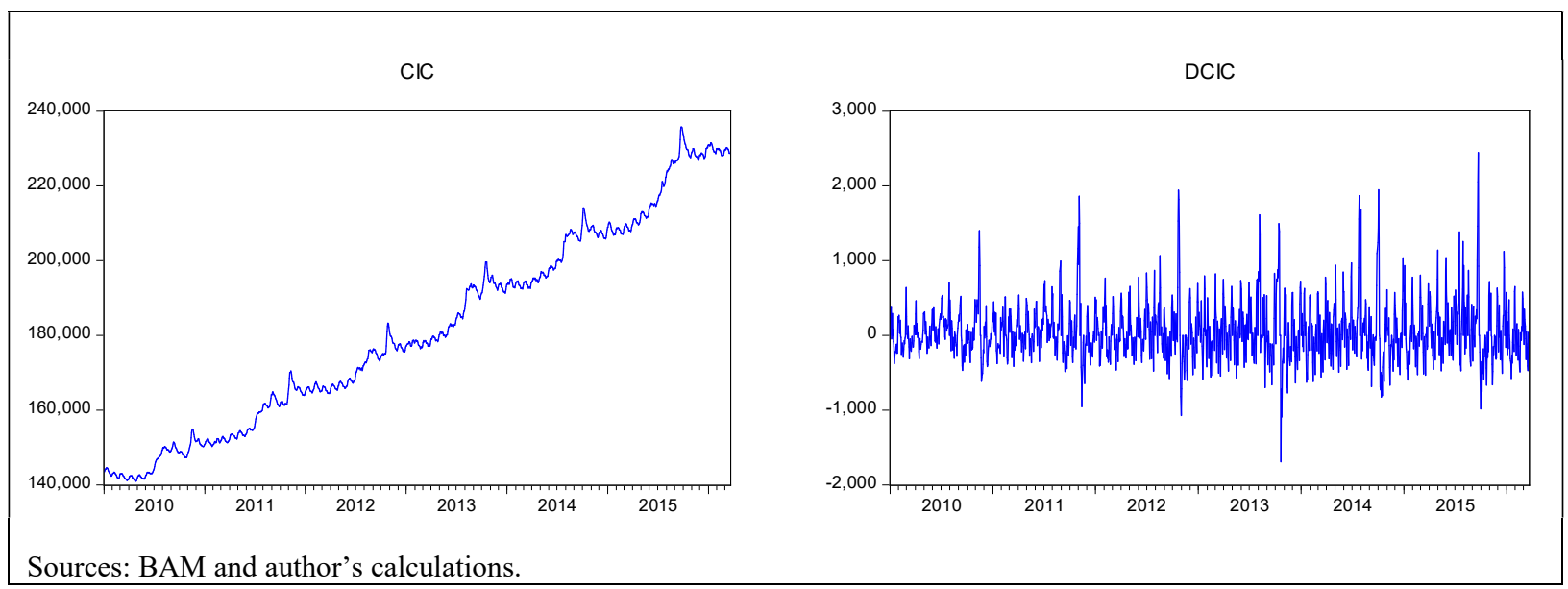


New Zealand

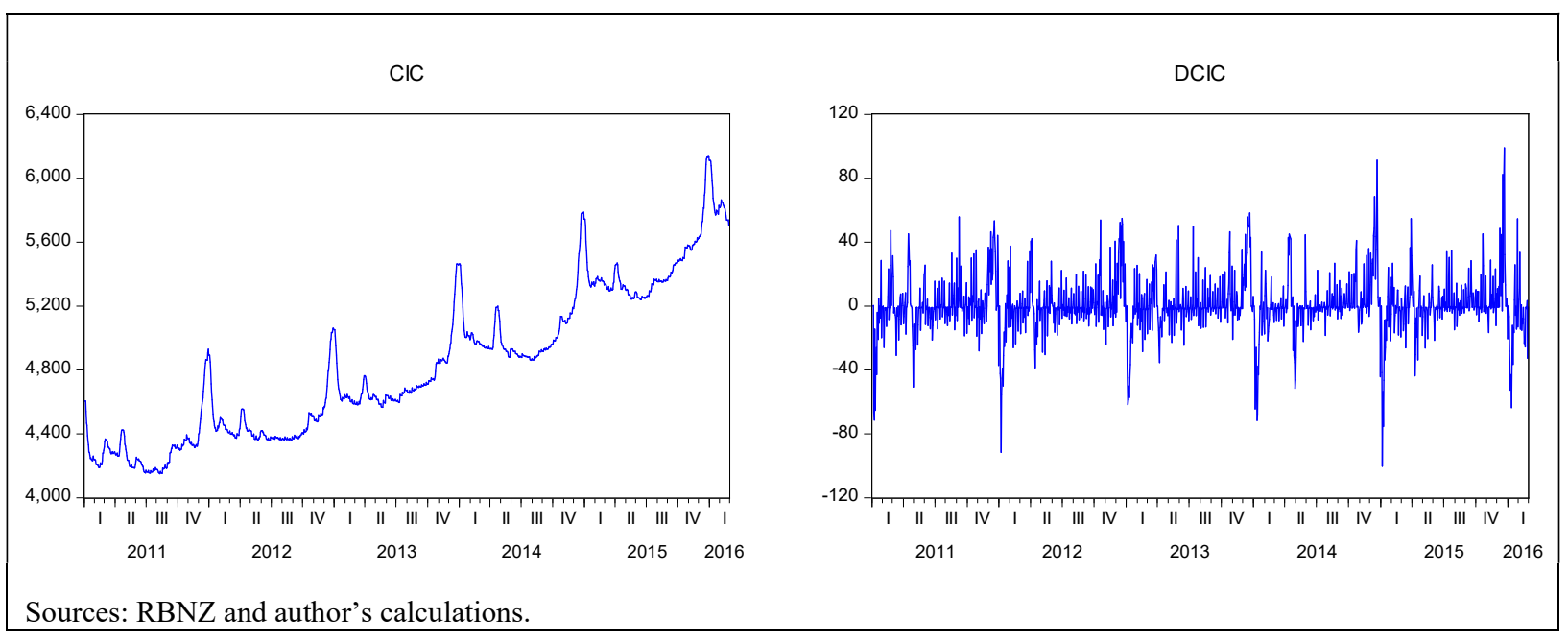

\section{Sudan}

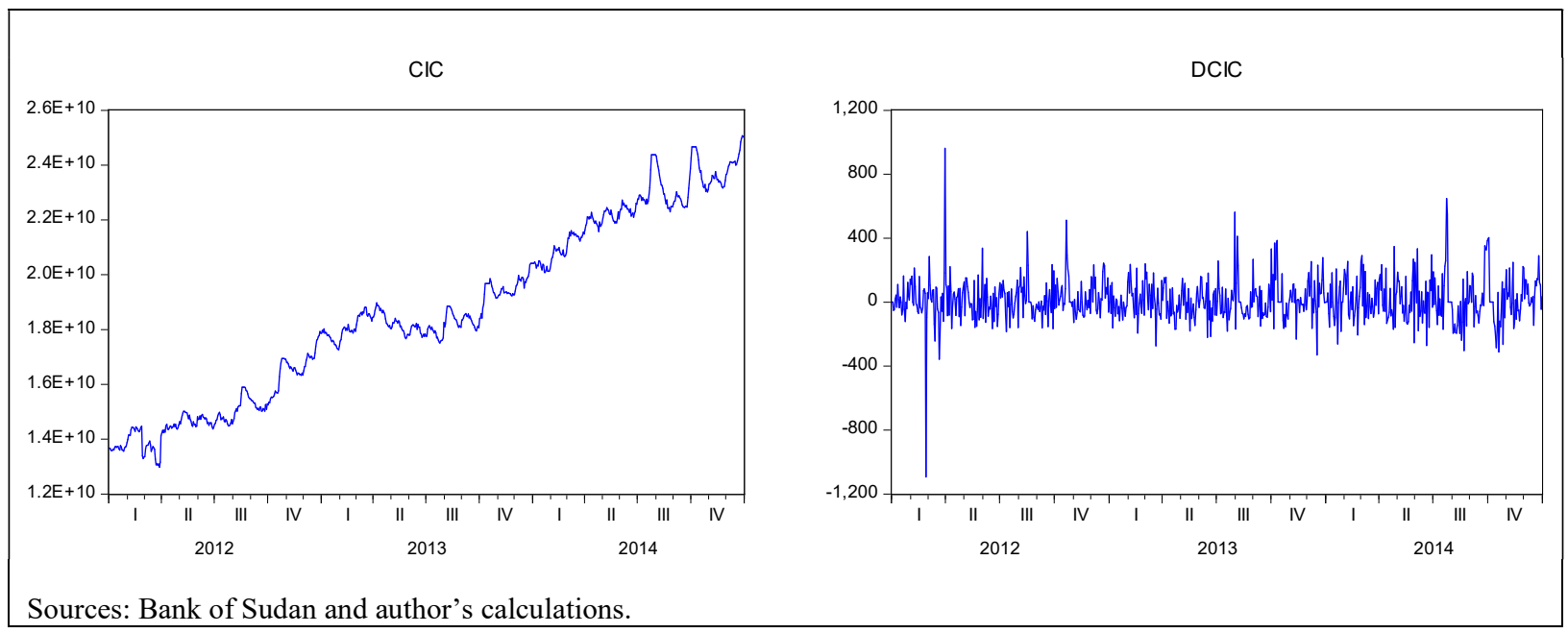




\section{Appendix IV. Brazil ARIMA Model of Currency in Circulation-Regression Results}

\begin{tabular}{|c|c|c|c|c|}
\hline Variable & Coefficient & Std. Error & t-Statistic & Prob. \\
\hline DAY & 34923.64 & 8071.438 & 4.326818 & 0.0000 \\
\hline MONTH & -952166.1 & 102847.2 & -9.258067 & 0.0000 \\
\hline$S(-13)$ & 415343.1 & 135112.7 & 3.074050 & 0.0022 \\
\hline$S(-9)$ & -1583162 & 154766.6 & -10.22935 & 0.0000 \\
\hline$S(-8)$ & -1660587 & 154494.9 & -10.74849 & 0.0000 \\
\hline$S(-7)$ & -1677334 & 151936.8 & -11.03968 & 0.0000 \\
\hline$S(-6)$ & -1411373 & 154962.3 & -9.107846 & 0.0000 \\
\hline$S(-1)$ & -596799.6 & 148256.4 & -4.025456 & 0.0001 \\
\hline$S(11)$ & -796436.6 & 131244.6 & -6.068337 & 0.0000 \\
\hline$S(12)$ & -894093.4 & 146211.9 & -6.115050 & 0.0000 \\
\hline$S(16)$ & 691795.8 & 157118.5 & 4.403020 & 0.0000 \\
\hline$S(17)$ & 1466382. & 157078.7 & 9.335333 & 0.0000 \\
\hline$S(18)$ & 2033679. & 150086.7 & 13.55003 & 0.0000 \\
\hline$S(19)$ & 2120215. & 159901.4 & 13.25952 & 0.0000 \\
\hline$S(20)$ & 1785731. & 157252.1 & 11.35585 & 0.0000 \\
\hline$S(21)$ & 1081496. & 173378.9 & 6.237761 & 0.0000 \\
\hline$S(22)$ & 2631228. & 153971.9 & 17.08902 & 0.0000 \\
\hline$S(23)$ & 2640102 & 141413.4 & 18.66940 & 0.0000 \\
\hline$S(24)$ & 1715511. & 146110.9 & 11.74115 & 0.0000 \\
\hline$S(25)$ & 346289.2 & 138089.1 & 2.507723 & 0.0123 \\
\hline$S(27)$ & -528189.9 & 135069.1 & -3.910515 & 0.0001 \\
\hline$S(34)$ & 547975.2 & 155507.0 & 3.523797 & 0.0004 \\
\hline $\mathrm{H}$ & -1256794 & 244066.8 & -5.149384 & 0.0000 \\
\hline MONDAY & 9117550. & 1111823. & 8.200541 & 0.0000 \\
\hline TUESDAY & 9885197. & 1113144. & 8.880432 & 0.0000 \\
\hline WEDNESDAY & 10317636 & 1108574. & 9.307126 & 0.0000 \\
\hline THURSDAY & 11211913 & 1101992. & 10.17422 & 0.0000 \\
\hline FRIDAY & 12366833 & 1100794. & 11.23447 & 0.0000 \\
\hline M2 & 709774.9 & 261034.4 & 2.719086 & 0.0067 \\
\hline M3 & 2779286. & 357651.8 & 7.770927 & 0.0000 \\
\hline M5 & -1515198. & 293876.3 & -5.155903 & 0.0000 \\
\hline T3 & 2306737. & 407138.6 & 5.665730 & 0.0000 \\
\hline $\mathrm{T} 4$ & -1380320 & 363890.3 & -3.793231 & 0.0002 \\
\hline $\mathrm{F} 2$ & 1344729. & 284093.2 & 4.733409 & 0.0000 \\
\hline F3 & -1709068 & 375741.5 & -4.548522 & 0.0000 \\
\hline W1 & -11397458 & 994705.1 & -11.45813 & 0.0000 \\
\hline W2 & -11093698 & 1077530. & -10.29548 & 0.0000 \\
\hline W3 & -11862310 & 1084411. & -10.93894 & 0.0000 \\
\hline W4 & -11873108 & 1088763. & -10.90514 & 0.0000 \\
\hline W5 & -7816951 & 930654.9 & -8.399409 & 0.0000 \\
\hline W6 & -9382312 & 990568.4 & -9.471645 & 0.0000 \\
\hline W7 & -10667086 & 970707.8 & -10.98898 & 0.0000 \\
\hline w8 & -10422072 & 981470.8 & -10.61883 & 0.0000 \\
\hline W9 & -7175944 & 785982.5 & -9.129903 & 0.0000 \\
\hline W10 & -8294541. & 890015.3 & -9.319548 & 0.0000 \\
\hline
\end{tabular}

CInternational Monetary Fund. Not for Redistribution 


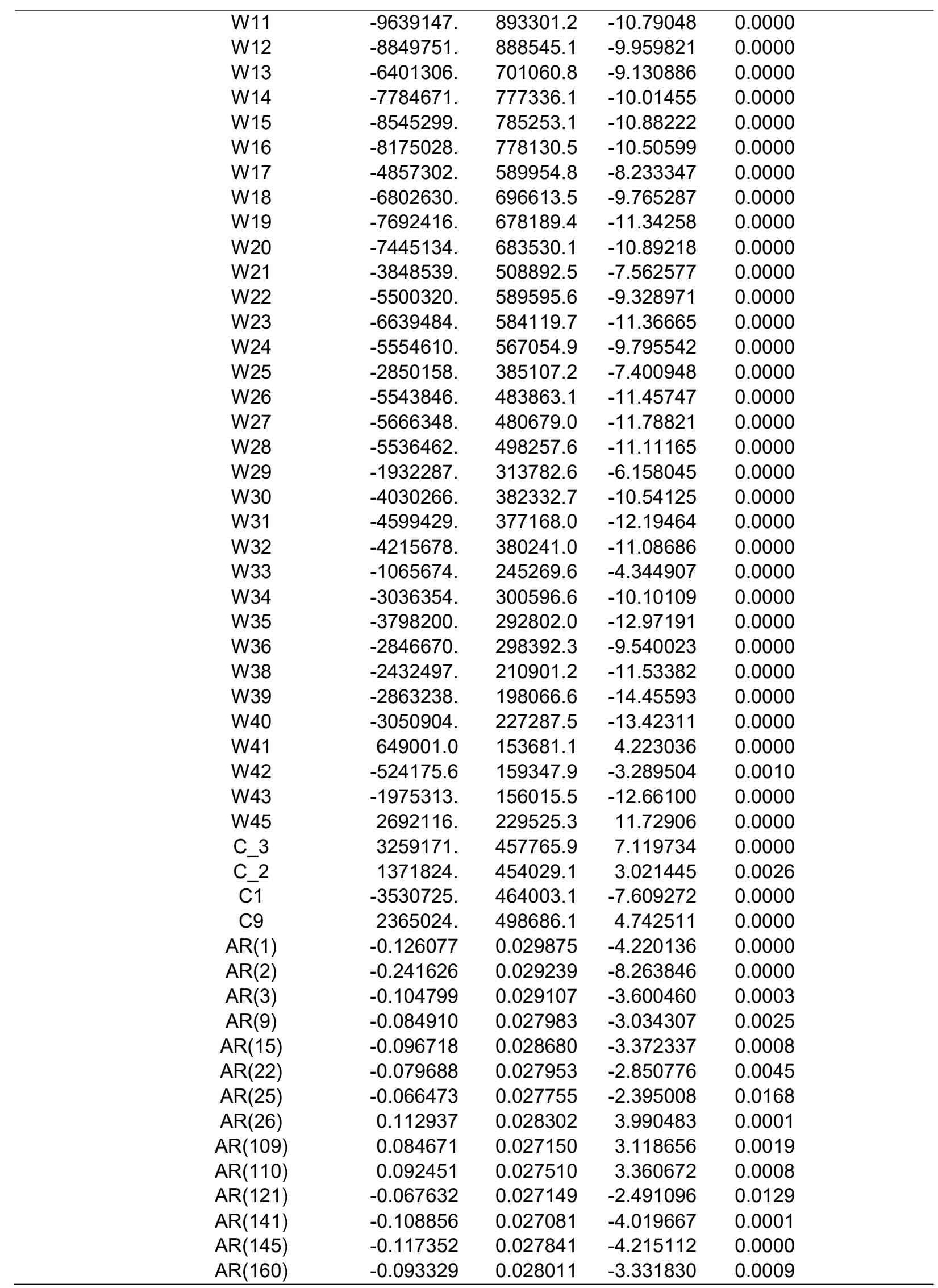

CInternational Monetary Fund. Not for Redistribution 


\begin{tabular}{|c|c|c|c|c|}
\hline AR(169) & -0.067367 & 0.027706 & -2.431470 & 0.0152 \\
\hline $\mathrm{AR}(173)$ & -0.085788 & 0.027194 & -3.154652 & 0.0017 \\
\hline$A R(180)$ & -0.102226 & 0.027804 & -3.676653 & 0.0003 \\
\hline $\mathrm{AR}(202)$ & -0.064254 & 0.027695 & -2.320067 & 0.0206 \\
\hline$A R(212)$ & -0.092589 & 0.026813 & -3.453129 & 0.0006 \\
\hline $\operatorname{AR}(221)$ & -0.088857 & 0.027772 & -3.199497 & 0.0014 \\
\hline $\operatorname{AR}(243)$ & -0.069307 & 0.027257 & -2.542685 & 0.0112 \\
\hline $\operatorname{AR}(260)$ & 0.298500 & 0.029181 & 10.22913 & 0.0000 \\
\hline $\mathrm{MA}(260)$ & -0.892123 & 0.007123 & -125.2501 & 0.0000 \\
\hline & \multirow{2}{*}{\multicolumn{3}{|c|}{$\begin{array}{l}\text { Mean dependent } \\
0.927939 \text { variable }\end{array}$}} & \\
\hline R-squared & & & & 60783.22 \\
\hline \multirow{3}{*}{$\begin{array}{l}\text { Adjusted R-squared } \\
\text { S.E. of regression } \\
\text { Sum squared } \\
\text { residuals }\end{array}$} & 0.919730 & \multirow{3}{*}{\multicolumn{2}{|c|}{$\begin{array}{l}\text { S.D. dependent variable } \\
\text { Akaike info criterion }\end{array}$}} & 2213940 \\
\hline & 627252.9 & & & 29.63351 \\
\hline & $3.59 E+14$ & & Schwarz criterion & 30.14156 \\
\hline \multirow{2}{*}{$\begin{array}{l}\text { Log likelihood } \\
\text { Durbin-Watson }\end{array}$} & -14978.46 & \multicolumn{2}{|c|}{ Hannan-Quinn criterion } & 29.82644 \\
\hline & & & & \\
\hline statistic & 2.103759 & & & \\
\hline
\end{tabular}

Sources: BCB and author's estimates.

CInternational Monetary Fund. Not for Redistribution 


\section{Appendix V. Kazakhstan ARIMA Model of Currency in Circulation-Regression Results}

\begin{tabular}{|c|c|c|c|c|}
\hline Variable & Coefficient & Std. Error & t-Statistic & Prob. \\
\hline$S$ & -2173.144 & 806.2254 & -2.695454 & 0.0071 \\
\hline $\mathrm{H}$ & -10604.67 & 1084.354 & -9.779712 & 0.0000 \\
\hline M2 & 4532.654 & 1264.057 & 3.585800 & 0.0004 \\
\hline M3 & 6925.541 & 1686.524 & 4.106400 & 0.0000 \\
\hline M4 & 3337.811 & 1388.684 & 2.403579 & 0.0164 \\
\hline $\mathrm{T} 2$ & 3872.691 & 1749.980 & 2.212991 & 0.0271 \\
\hline T3 & 12059.04 & 1996.092 & 6.041327 & 0.0000 \\
\hline $\mathrm{T} 4$ & 8161.730 & 1509.718 & 5.406130 & 0.0000 \\
\hline WED1 & 7075.015 & 1644.841 & 4.301338 & 0.0000 \\
\hline WED5 & -4752.436 & 1558.074 & -3.050199 & 0.0023 \\
\hline $\mathrm{TH} 1$ & 5799.708 & 1718.350 & 3.375162 & 0.0008 \\
\hline $\mathrm{TH} 2$ & 9552.187 & 1738.796 & 5.493565 & 0.0000 \\
\hline $\mathrm{F} 2$ & 6641.980 & 1371.445 & 4.843053 & 0.0000 \\
\hline W1 & 12307.90 & 2888.532 & 4.260953 & 0.0000 \\
\hline W46 & 5686.026 & 2686.372 & 2.116619 & 0.0345 \\
\hline W47 & -13794.39 & 2922.722 & -4.719707 & 0.0000 \\
\hline FRIDAY & 11347.28 & 1181.856 & 9.601240 & 0.0000 \\
\hline $\mathrm{AR}(1)$ & 0.428279 & 0.019568 & 21.88662 & 0.0000 \\
\hline $\mathrm{AR}(20)$ & 0.103620 & 0.023788 & 4.356003 & 0.0000 \\
\hline $\mathrm{AR}(21)$ & -0.086910 & 0.023528 & -3.693933 & 0.0002 \\
\hline $\mathrm{AR}(31)$ & -0.039572 & 0.016030 & -2.468629 & 0.0137 \\
\hline $\mathrm{AR}(40)$ & 0.086982 & 0.017850 & 4.872929 & 0.0000 \\
\hline $\operatorname{AR}(86)$ & -0.097740 & 0.022107 & -4.421163 & 0.0000 \\
\hline $\mathrm{AR}(87)$ & 0.072454 & 0.022592 & 3.207096 & 0.0014 \\
\hline $\mathrm{AR}(90)$ & 0.051655 & 0.017933 & 2.880544 & 0.0041 \\
\hline $\mathrm{AR}(240)$ & 0.142746 & 0.022973 & 6.213572 & 0.0000 \\
\hline $\mathrm{AR}(243)$ & -0.101612 & 0.021468 & -4.733057 & 0.0000 \\
\hline $\operatorname{AR}(250)$ & 0.135573 & 0.020331 & 6.668288 & 0.0000 \\
\hline$A R(255)$ & -0.115754 & 0.022012 & -5.258617 & 0.0000 \\
\hline$A R(260)$ & 0.617606 & 0.024059 & 25.67065 & 0.0000 \\
\hline $\mathrm{MA}(260)$ & -0.836121 & 0.008457 & -98.86712 & 0.0000 \\
\hline R-squared & 0.748668 & \multicolumn{2}{|c|}{ Mean dependent variable } & 72.84277 \\
\hline Adjusted R-squared & 0.741218 & \multicolumn{2}{|c|}{ S.D. dependent variable } & 9345.914 \\
\hline S.E. of regression & 4754.329 & \multicolumn{2}{|c|}{ Akaike info criterion } & 19.80077 \\
\hline Sum squared residuals & $2.29 \mathrm{E}+10$ & \multicolumn{2}{|c|}{ Schwarz criterion } & 19.94789 \\
\hline Log likelihood & -10295.10 & \multicolumn{2}{|c|}{ Hannan-Quinn criterion } & 19.85657 \\
\hline Durbin-Watson statistic & 2.166946 & & & \\
\hline
\end{tabular}

Sources: NBK and author's estimates. 


\section{Appendix VI. Morocco ARIMA Model of Currency in Circulation-Regression Results}

\begin{tabular}{|c|c|c|c|c|}
\hline Variable & Coefficient & Std. Error & t-Statistic & Prob. \\
\hline MONTH & 22.90060 & 9.852181 & 2.324420 & 0.0203 \\
\hline $\mathrm{H}$ & -200.8700 & 29.11243 & -6.899801 & 0.0000 \\
\hline$S$ & 213.3831 & 30.13089 & 7.081872 & 0.0000 \\
\hline S1 & 155.3291 & 30.82931 & 5.038357 & 0.0000 \\
\hline MONDAY & 95.29994 & 19.95113 & 4.776668 & 0.0000 \\
\hline WEDNESDAY & -331.2694 & 17.29620 & -19.15272 & 0.0000 \\
\hline FRIDAY & 185.2504 & 20.83604 & 8.890866 & 0.0000 \\
\hline M2 & 244.0248 & 75.62887 & 3.226609 & 0.0013 \\
\hline $\mathrm{T} 4$ & 187.2851 & 57.23728 & 3.272083 & 0.0011 \\
\hline W27 & 243.8771 & 113.4847 & 2.148987 & 0.0318 \\
\hline W28 & 362.1811 & 116.1466 & 3.118311 & 0.0019 \\
\hline W29 & 235.7071 & 97.81401 & 2.409748 & 0.0161 \\
\hline AF1 & 722.7536 & 88.13524 & 8.200506 & 0.0000 \\
\hline AF2 & 1339.386 & 91.91315 & 14.57230 & 0.0000 \\
\hline AF3 & 951.3863 & 91.39197 & 10.40996 & 0.0000 \\
\hline AF4 & 280.7579 & 87.52496 & 3.207746 & 0.0014 \\
\hline AA_1 & 1080.499 & 92.60996 & 11.66720 & 0.0000 \\
\hline$A A^{-} 2$ & 1987.013 & 92.71267 & 21.43195 & 0.0000 \\
\hline AA_3 & 1603.770 & 91.50602 & 17.52639 & 0.0000 \\
\hline AA_ 4 & 1330.060 & 91.48371 & 14.53877 & 0.0000 \\
\hline AA_5 & 1136.380 & 91.72948 & 12.38838 & 0.0000 \\
\hline AA_6 & 690.7200 & 91.29693 & 7.565644 & 0.0000 \\
\hline AA_7 & 506.2355 & 90.85203 & 5.572088 & 0.0000 \\
\hline AA_8 & 377.0366 & 90.82744 & 4.151131 & 0.0000 \\
\hline AA_9 & 239.1390 & 91.86135 & 2.603261 & 0.0093 \\
\hline AA_10 & 200.7271 & 88.37275 & 2.271369 & 0.0233 \\
\hline $\mathrm{AA} 1$ & -535.0637 & 89.43439 & -5.982752 & 0.0000 \\
\hline AA2 & -630.7206 & 92.33846 & -6.830529 & 0.0000 \\
\hline AA3 & -644.0249 & 91.54607 & -7.034981 & 0.0000 \\
\hline AA4 & -570.3301 & 91.74881 & -6.216213 & 0.0000 \\
\hline AA5 & -527.5888 & 92.04464 & -5.731880 & 0.0000 \\
\hline AA6 & -418.5062 & 91.42293 & -4.577694 & 0.0000 \\
\hline AA7 & -185.7298 & 90.87084 & -2.043887 & 0.0412 \\
\hline AA8 & -295.5614 & 91.82959 & -3.218586 & 0.0013 \\
\hline AA9 & -283.9825 & 88.28493 & -3.216659 & 0.0013 \\
\hline $\operatorname{AR}(1)$ & 0.338927 & 0.023967 & 14.14165 & 0.0000 \\
\hline $\mathrm{AR}(2)$ & -0.066124 & 0.019313 & -3.423837 & 0.0006 \\
\hline $\operatorname{AR}(20)$ & 0.032177 & 0.013666 & 2.354602 & 0.0187 \\
\hline $\operatorname{AR}(260)$ & 0.676819 & 0.018990 & 35.64051 & 0.0000 \\
\hline $\mathrm{MA}(260)$ & -0.853959 & 0.007080 & -120.6159 & 0.0000 \\
\hline R-squared & 0.805276 & \multicolumn{2}{|c|}{ Mean dependent variable } & 57.19665 \\
\hline Adjusted R-squared & 0.799527 & \multicolumn{2}{|c|}{ S.D. dependent variable } & 398.4656 \\
\hline S.E. of regression & 178.4099 & \multicolumn{2}{|c|}{ Akaike info criterion } & 13.23499 \\
\hline Sum squared residuals & 42047565 & \multicolumn{2}{|c|}{ Schwarz criterion } & 13.38829 \\
\hline Log likelihood & -8966.414 & \multirow{2}{*}{\multicolumn{2}{|c|}{ Hannan-Quinn criterion }} & 13.29238 \\
\hline Durbin-Watson statistic & 1.813386 & & & \\
\hline
\end{tabular}

Sources: BAM and author's estimates.

CInternational Monetary Fund. Not for Redistribution 


\section{Appendix VII. New Zealand ARIMA Model of Currency in Circulation-Regression Results}

\begin{tabular}{|c|c|c|c|c|}
\hline Variable & Coefficient & Std. Error & t-Statistic & Prob. \\
\hline MONTH & 1.493665 & 0.119722 & 12.47608 & 0.0000 \\
\hline MONDAY & -9.231777 & 1.193763 & -7.733342 & 0.0000 \\
\hline TUESDAY & -10.43762 & 1.196131 & -8.726153 & 0.0000 \\
\hline WEDNESDAY & -8.023829 & 1.123481 & -7.141937 & 0.0000 \\
\hline FRIDAY & -19.76918 & 1.124588 & -17.57904 & 0.0000 \\
\hline M1 & 19.28935 & 2.323473 & 8.301948 & 0.0000 \\
\hline $\mathrm{T} 2$ & 16.33036 & 5.502787 & 2.967653 & 0.0031 \\
\hline $\mathrm{T} 4$ & 23.04182 & 5.564054 & 4.141193 & 0.0000 \\
\hline $\mathrm{TH} 1$ & 20.67596 & 3.816438 & 5.417606 & 0.0000 \\
\hline $\mathrm{TH} 4$ & 13.25062 & 3.845394 & 3.445843 & 0.0006 \\
\hline $\mathrm{F} 2$ & -14.17081 & 3.252311 & -4.357151 & 0.0000 \\
\hline W1 & 59.43353 & 12.16764 & 4.884558 & 0.0000 \\
\hline W2 & 79.55021 & 17.62239 & 4.514155 & 0.0000 \\
\hline W46 & 13.23950 & 2.749884 & 4.814565 & 0.0000 \\
\hline C_3 & 41.80081 & 4.129616 & 10.12220 & 0.0000 \\
\hline C_6 & 24.46098 & 4.011631 & 6.097514 & 0.0000 \\
\hline C_8 & 14.13786 & 4.272577 & 3.308978 & 0.0010 \\
\hline C_12 & 8.534900 & 4.239624 & 2.013126 & 0.0443 \\
\hline$\overline{\mathrm{C}} 1$ & -22.99154 & 4.279038 & -5.373063 & 0.0000 \\
\hline $\mathrm{C} 4$ & -27.61013 & 4.482296 & -6.159820 & 0.0000 \\
\hline C5 & -35.64586 & 11.32861 & -3.146535 & 0.0017 \\
\hline C6 & -57.98100 & 12.69245 & -4.568149 & 0.0000 \\
\hline $\mathrm{C} 7$ & -73.43441 & 12.90440 & -5.690649 & 0.0000 \\
\hline $\mathrm{C} 8$ & -109.1587 & 12.86747 & -8.483310 & 0.0000 \\
\hline C9 & -105.8669 & 12.91558 & -8.196834 & 0.0000 \\
\hline C10 & -122.9535 & 17.14077 & -7.173159 & 0.0000 \\
\hline C11 & -115.5805 & 18.05175 & -6.402731 & 0.0000 \\
\hline C12 & -113.7686 & 18.17846 & -6.258432 & 0.0000 \\
\hline C13 & -102.8814 & 18.16861 & -5.662589 & 0.0000 \\
\hline C14 & -97.70983 & 18.20298 & -5.367792 & 0.0000 \\
\hline C15 & -92.39099 & 18.11805 & -5.099390 & 0.0000 \\
\hline E_1 & 14.57095 & 4.175553 & 3.489585 & 0.0005 \\
\hline E_3 & 29.32017 & 4.712127 & 6.222280 & 0.0000 \\
\hline E_4 & 35.26128 & 4.740170 & 7.438821 & 0.0000 \\
\hline E_5 & 41.51883 & 4.762392 & 8.718062 & 0.0000 \\
\hline E_6 & 23.77389 & 4.822830 & 4.929447 & 0.0000 \\
\hline E_7 & 12.84009 & 4.609730 & 2.785433 & 0.0054 \\
\hline$\overline{\mathrm{E} 2}$ & -10.72453 & 4.185984 & -2.562010 & 0.0105 \\
\hline E3 & -24.19218 & 4.338271 & -5.576455 & 0.0000 \\
\hline E4 & -23.53013 & 4.240648 & -5.548711 & 0.0000 \\
\hline E6 & -13.43170 & 4.100269 & -3.275810 & 0.0011 \\
\hline E7 & -11.13869 & 4.341613 & -2.565564 & 0.0104 \\
\hline E8 & -20.99435 & 4.409155 & -4.761535 & 0.0000 \\
\hline E9 & -18.44959 & 4.198292 & -4.394546 & 0.0000 \\
\hline
\end{tabular}

CInternational Monetary Fund. Not for Redistribution 


\begin{tabular}{crrrr}
\hline $\mathrm{AR}(1)$ & 0.315085 & 0.029357 & 10.73282 & 0.0000 \\
$\mathrm{AR}(2)$ & 0.067136 & 0.028736 & 2.336269 & 0.0196 \\
$\mathrm{AR}(5)$ & 0.111316 & 0.027942 & 3.983741 & 0.0001 \\
$\mathrm{AR}(7)$ & -0.060875 & 0.028058 & -2.169634 & 0.0302 \\
$\mathrm{AR}(35)$ & 0.066319 & 0.027009 & 2.455465 & 0.0142 \\
$\mathrm{AR}(77)$ & 0.147271 & 0.034943 & 4.214651 & 0.0000 \\
$\mathrm{MA}(15)$ & -0.134845 & 0.023356 & -5.773560 & 0.0000 \\
$\mathrm{MA}(77)$ & -0.174602 & 0.028609 & -6.103063 & 0.0000 \\
$\mathrm{MA}(173)$ & 0.080942 & 0.019135 & 4.229957 & 0.0000 \\
$\mathrm{MA}(199)$ & -0.071679 & 0.018498 & -3.875020 & 0.0001 \\
$\mathrm{MA}(204)$ & 0.111615 & 0.014764 & 7.559692 & 0.0000 \\
$\mathrm{MA}(206)$ & 0.077509 & 0.015321 & 5.058910 & 0.0000 \\
$\mathrm{MA}(216)$ & 0.096450 & 0.017048 & 5.657403 & 0.0000 \\
$\mathrm{MA}(220)$ & 0.229144 & 0.023439 & 9.776031 & 0.0000 \\
$\mathrm{MA}(235)$ & 0.300717 & 0.026004 & 11.56413 & 0.0000 \\
$\mathrm{MA}(236)$ & -0.211290 & 0.017931 & -11.78379 & 0.0000 \\
\hline \hline R-squared & 0.726685 & Mean dependent var & 1.012188 \\
Adjusted R-squared & 0.713336 & S.D. dependent var & 18.09531 \\
S.E. of regression & 9.688419 & Akaike info criterion & 7.425902 \\
Sum squared resid & 113389.5 & Schwarz criterion & 7.669366 \\
Log likelihood & -4648.022 & Hannan-Quinn criter. & 7.517363 \\
Durbin-Watson stat & 1.976281 & & & \\
\hline \hline
\end{tabular}

Sources: RBNZ and author's estimates.

CInternational Monetary Fund. Not for Redistribution 
Appendix VIII. Sudan ARIMA Model of Currency in Circulation-Regression Results

\begin{tabular}{|c|c|c|c|c|}
\hline Variable & Coefficient & Std. Error & t-Statistic & Prob. \\
\hline DAY & -1.863491 & 0.289089 & -6.446082 & 0.0000 \\
\hline$S(-1)$ & 71.43419 & 20.26931 & 3.524254 & 0.0005 \\
\hline SUNDAY & 108.7029 & 12.18282 & 8.922635 & 0.0000 \\
\hline WEDNESDAY & 90.82763 & 12.56259 & 7.230006 & 0.0000 \\
\hline MON5 & -243.7973 & 54.76926 & -4.451353 & 0.0000 \\
\hline W5 & 83.97357 & 21.36826 & 3.929826 & 0.0001 \\
\hline w9 & 45.15275 & 20.92127 & 2.158222 & 0.0314 \\
\hline W13 & 45.86034 & 20.92032 & 2.192143 & 0.0289 \\
\hline W29 & -235.3133 & 22.44648 & -10.48330 & 0.0000 \\
\hline W30 & -80.34377 & 20.75716 & -3.870653 & 0.0001 \\
\hline W31 & -62.99848 & 21.65877 & -2.908682 & 0.0038 \\
\hline W48 & 64.51586 & 21.38705 & 3.016585 & 0.0027 \\
\hline FITR_1 & 643.2825 & 54.34184 & 11.83770 & 0.0000 \\
\hline FITR_2 & 411.1399 & 55.86069 & 7.360093 & 0.0000 \\
\hline FITR_3 & 380.2881 & 53.81831 & 7.066148 & 0.0000 \\
\hline FITR_4 & 277.1591 & 55.99680 & 4.949551 & 0.0000 \\
\hline ADHA_1 & 408.7681 & 52.59646 & 7.771779 & 0.0000 \\
\hline ADHA_2 & 238.1701 & 54.55351 & 4.365807 & 0.0000 \\
\hline ADHA_3 & 308.4898 & 53.20117 & 5.798552 & 0.0000 \\
\hline ADHA_4 & 332.0770 & 53.67513 & 6.186795 & 0.0000 \\
\hline ADHA_6 & 391.9273 & 53.91422 & 7.269461 & 0.0000 \\
\hline ADHA_7 & -156.7157 & 53.93275 & -2.905762 & 0.0038 \\
\hline $\mathrm{ADHA} \overline{3}$ & -152.9064 & 53.83508 & -2.840274 & 0.0047 \\
\hline ADHA4 & -353.5587 & 52.97900 & -6.673563 & 0.0000 \\
\hline ADHA5 & -94.06754 & 52.68151 & -1.785589 & 0.0748 \\
\hline ADHA7 & -268.5866 & 51.97756 & -5.167357 & 0.0000 \\
\hline $\mathrm{AR}(1)$ & -0.195444 & 0.038022 & -5.140317 & 0.0000 \\
\hline$A R(5)$ & 0.173715 & 0.037461 & 4.637185 & 0.0000 \\
\hline $\operatorname{AR}(7)$ & -0.118985 & 0.037943 & -3.135920 & 0.0018 \\
\hline$A R(8)$ & -0.158408 & 0.037434 & -4.231691 & 0.0000 \\
\hline $\mathrm{AR}(10)$ & -0.106730 & 0.036614 & -2.915016 & 0.0037 \\
\hline $\mathrm{AR}(34)$ & -0.137654 & 0.037149 & -3.705474 & 0.0002 \\
\hline $\operatorname{AR}(58)$ & -0.126114 & 0.036249 & -3.479075 & 0.0005 \\
\hline $\mathrm{AR}(61)$ & 0.132937 & 0.037112 & 3.582064 & 0.0004 \\
\hline $\operatorname{AR}(63)$ & 0.154949 & 0.037107 & 4.175767 & 0.0000 \\
\hline $\mathrm{AR}(87)$ & -0.107046 & 0.037174 & -2.879633 & 0.0042 \\
\hline$A R(105)$ & -0.113127 & 0.037722 & -2.999000 & 0.0029 \\
\hline $\operatorname{AR}(133)$ & 0.101055 & 0.036084 & 2.800562 & 0.0053 \\
\hline $\operatorname{AR}(168)$ & -0.120273 & 0.036351 & -3.308696 & 0.0010 \\
\hline $\operatorname{AR}(190)$ & -0.141373 & 0.036415 & -3.882275 & 0.0001 \\
\hline $\operatorname{AR}(193)$ & 0.095827 & 0.036402 & 2.632434 & 0.0088 \\
\hline $\mathrm{AR}(195)$ & 0.117499 & 0.036303 & 3.236651 & 0.0013 \\
\hline$A R(196)$ & 0.134100 & 0.037628 & 3.563849 & 0.0004 \\
\hline$A R(209)$ & 0.079870 & 0.035942 & 2.222200 & 0.0267 \\
\hline $\operatorname{AR}(215)$ & 0.137768 & 0.036866 & 3.736976 & 0.0002 \\
\hline
\end{tabular}

CInternational Monetary Fund. Not for Redistribution 


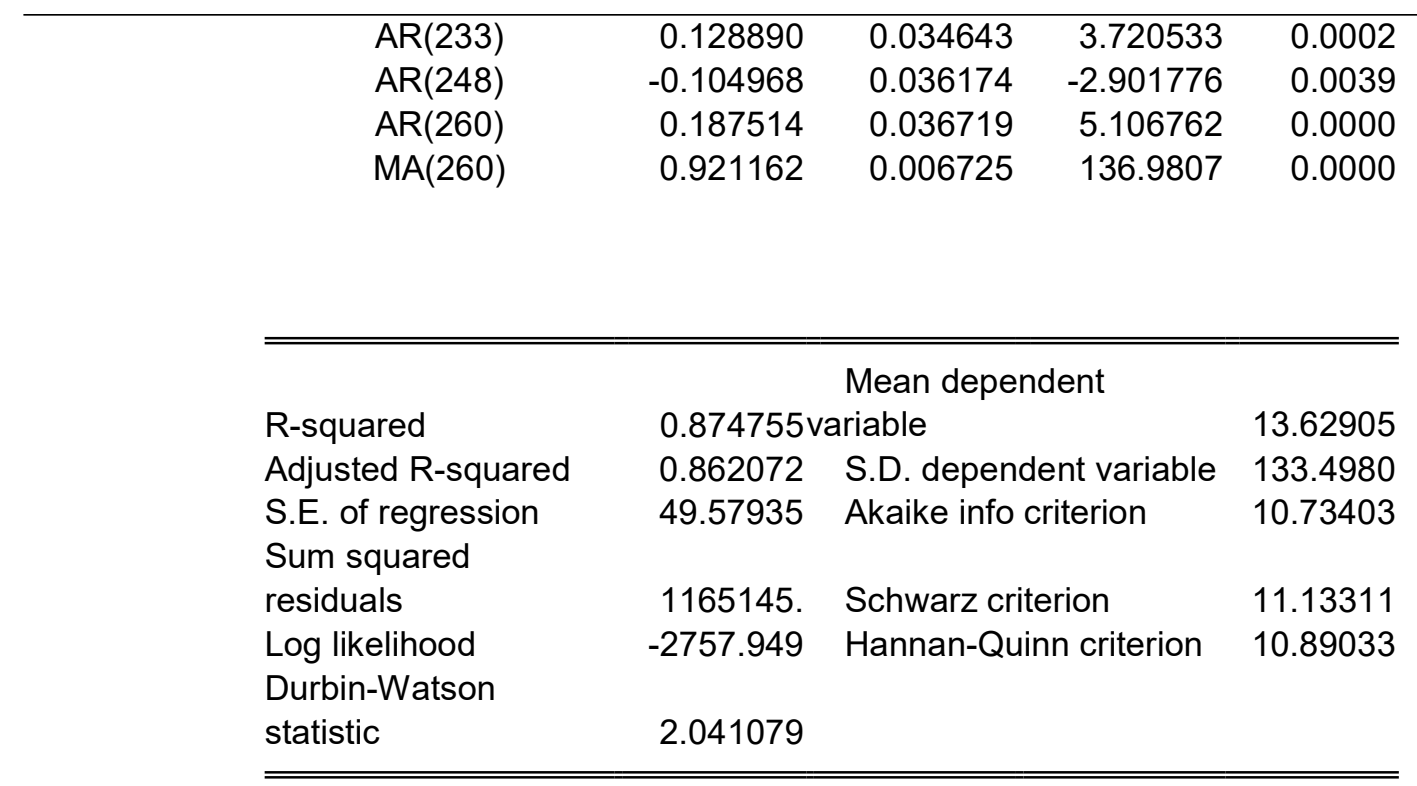

Sources: Bank of Sudan and author's estimates. 


\section{Appendix IX. ARIMA Model Residuals}

\section{Brazil}

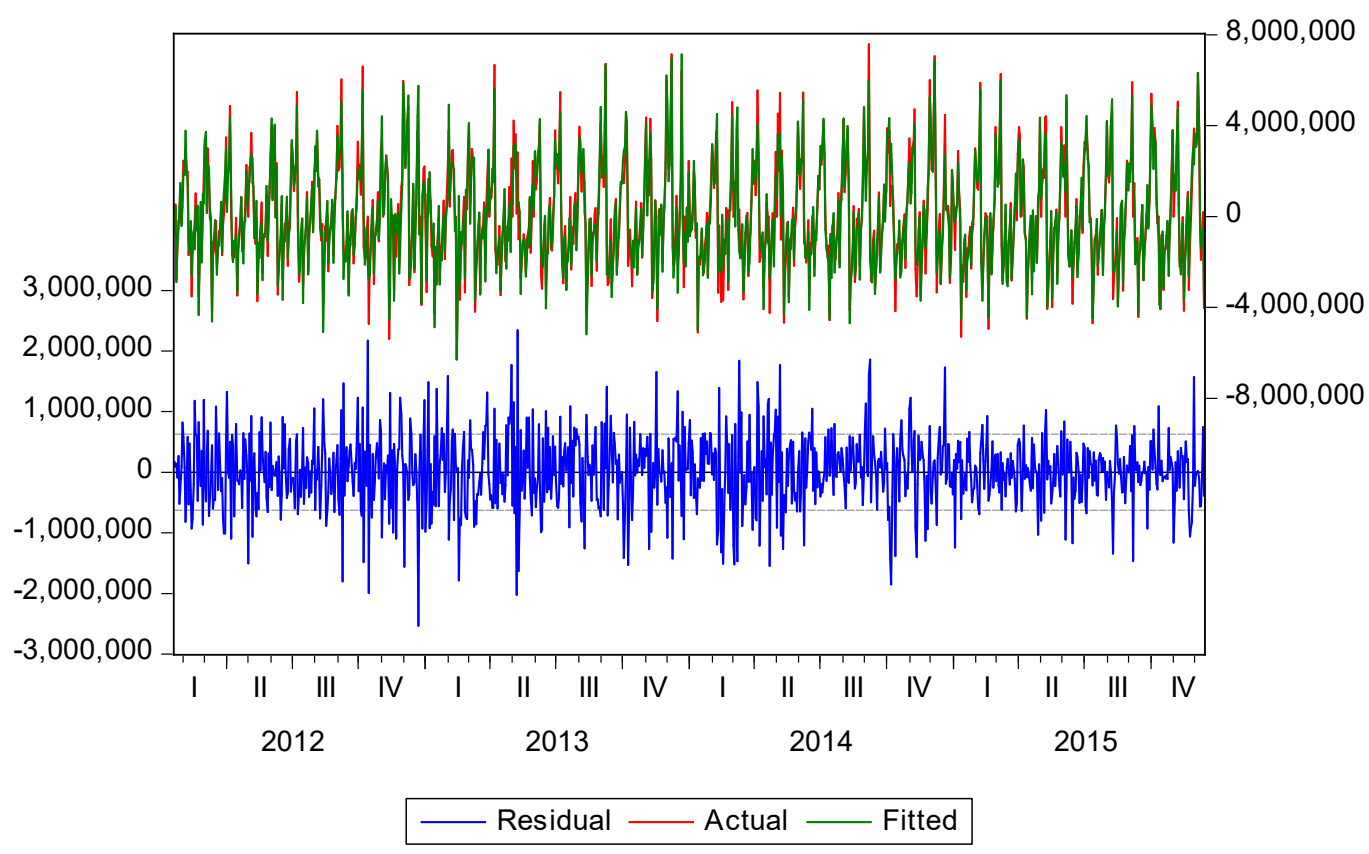

Sources: BCB and author's estimates.

\section{Kazakhstan}

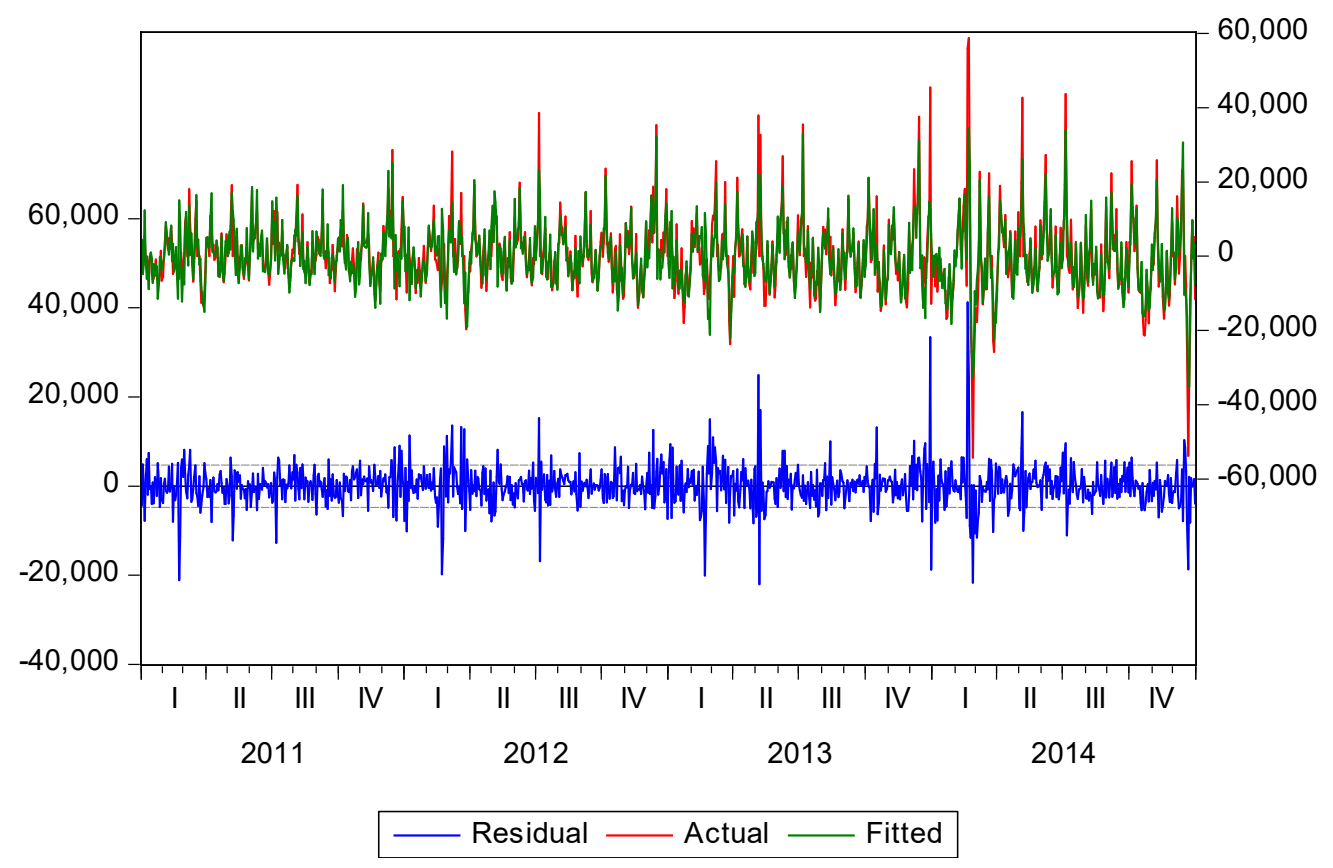

Sources: NBK and author's estimates. 


\section{Morocco}

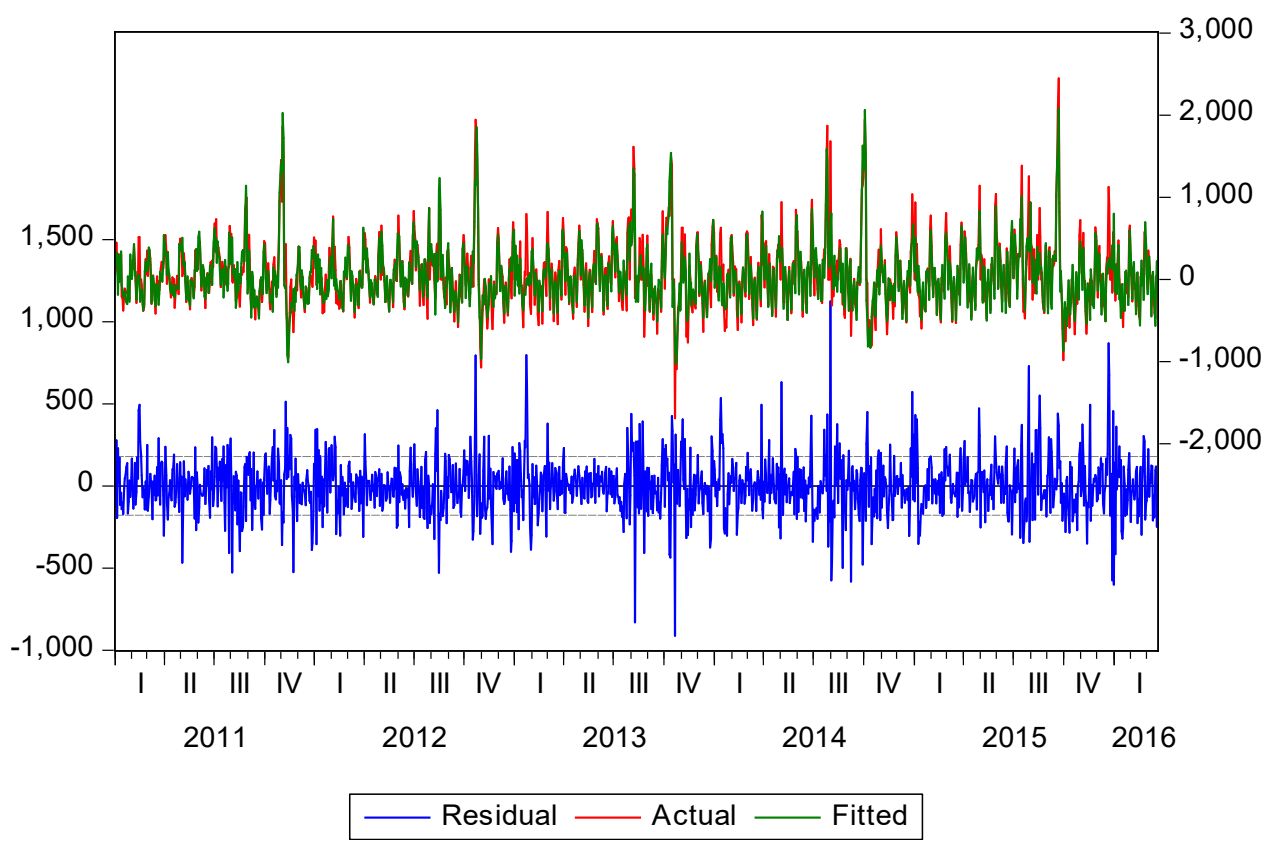

Sources: BAM and author's estimates.

New Zealand

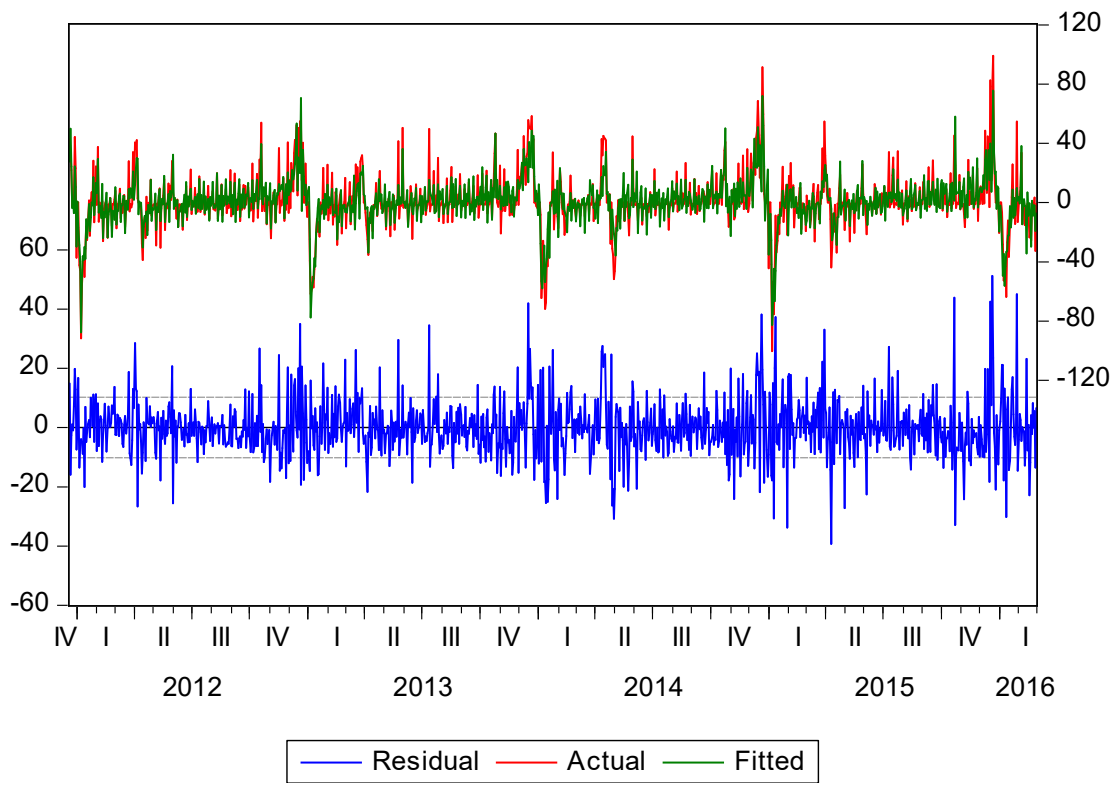

Sources: RBNZ and author's estimates. 


\section{Sudan}

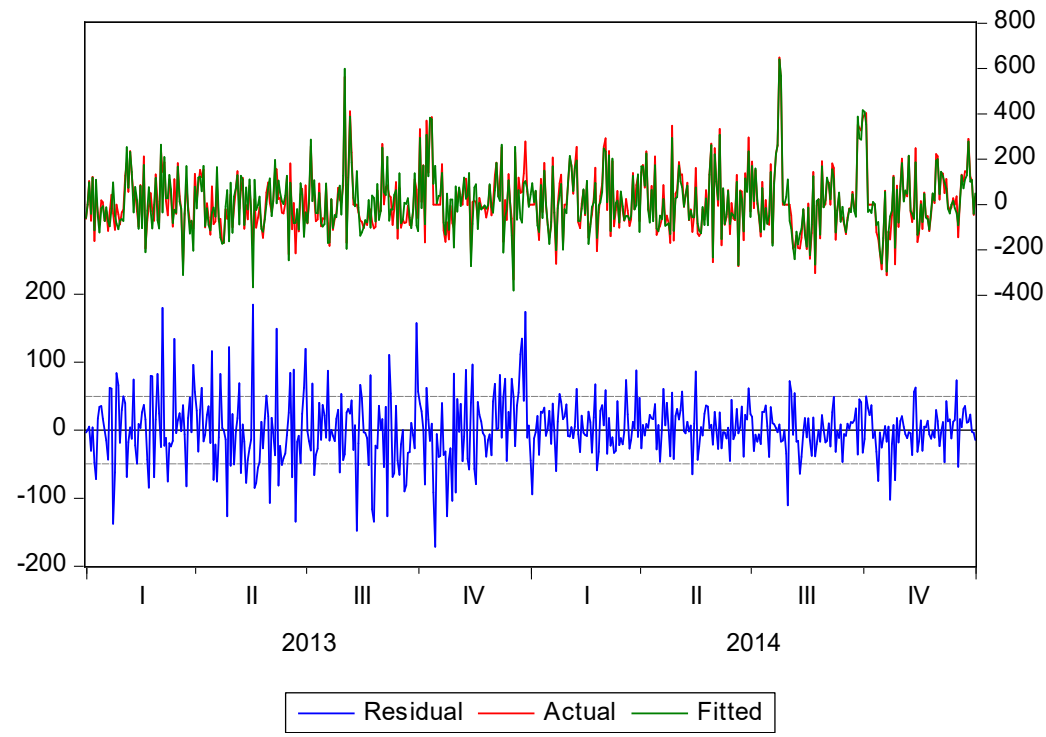

Sources: Bank of Sudan and author's estimates. 


\section{REFERENCES}

Alvarez, Fernando, and Francesco Lippi. 2007. "Financial Innovation and the Transactions Demand for Cash," National Bureau of Economic Research Working Paper 13416, August.

Balli, Faruk, and Elsayed Elsamadasy. 2010. "Modeling the Currency in Circulation for the State of Qatar," March.

Bank Al-Maghrib. 2007. Monetary Policy Report, March.

Bell, William R., and Steven C. Hillmer. 1983. "Modeling Time Series with Calendar Variation," Journal of the American Statistical Association, Vol. 78, No. 383, September.

Box, G.E.P., and G.C. Tiao. 1975. "Intervention Analysis with Applications to Economic and Environmental Problems," Journal of the American Statistical Association, Vol. 70, No. 349, March.

Cabrero, Alberto, Gonzalo Camba-Mendez, Astrid Hirsh, and Fernando Nieto. 2002. "Modeling the Daily Banknotes in Circulation in the Context of Liquidity Management of the European Central Bank," European Central Bank Working Paper No. 142, May.

Calvo, Guillermo, and Carlos A. Végh. 1992. "Currency Substitution in Developing Countries: An Introduction,” IMF Working Paper 92/40, May. Washington: International Monetary Fund.

Cassino, Vincenzo, Peter Misich, and John Barry. 1997. "Forecasting the Demand of Currency,” Reserve Bank Bulletin, Reserve Bank of New Zealand, Vol. 60, No.1.

Christiano, Lawrence J., Martin Eichenbaum, and Charles L. Evans. 2005. "Nominal Rigidities and the Dynamic Effects of a Shock to Monetary Policy," Journal of Political Economy, Vol. 113, No. 1, February.

Cusbert, Tom, and Thomas Rohling. 2013. "Currency Demand during the Global Financial Crisis: Evidence from Australia," Research Discussion Paper 2013-01, Reserve Bank of Australia, January.

DeBroeck, Mark, Kornelia Krainyak, and Henri Lorie. 1997. "Explaining and Forecasting the Velocity of Money in Transition Economies, with Special Reference to the Baltics, Russia, and other Countries of the Former Soviet Union," IMF Working Paper 97/108, September. Washington: International Monetary Fund.

Della Valle, Guido, Romain Veyrune, Erald Themeli, Ezequiel Cabezon, and Shaoyu Guo, "The Effective Lower Policy Rate Bound in Albania," IMF Working Paper, forthcoming. Washington: International Monetary Fund. 
Dheerasinghe, Rupa. 2006. "Modeling and Forecasting Currency in Circulation in Sri Lanka," Central Bank of Sri Lanka Staff Studies, No. 36.

Diebold, Francis X., and Roberto S. Mariano. 1995. "Comparing Predictive Accuracy," Journal of Business and Economic Statistics, Vol. 13, No. 3.

Friedman, Milton. 1968. "The Role of Monetary Policy," The American Economic Review, Vol. 58, No. 1, March.

Gerst, Jeremy, and Daniel J. Wilson. 2011. “An Analytical Framework for the Forecasting and Risk Assessment of Demand for FED Cash Services," Federal Reserve Bank of San Francisco technical paper prepared as part of the Long-Term Strategic Planning Initiative of the Federal Reserve Cash Product Office, March.

Harvey, Andrew, Siem Jan Koopman, and Marco Riani. 1997. "The Modeling and Seasonal Adjustment of Weekly Observations," Journal of Business and Economic Statistics, Vol. 15, No. 3, July.

Hellerstein, Rebecca, and William Ryan. 2011. "Cash Dollars Abroad," Federal Reserve Bank of New York, Staff Report No. 400, February.

Hlaváček, Marek, Michael Koňák, and Josef Čada. 2005. “The Application of Structured Feedforward Neural Networks to the Modeling of Daily Series of Currency in Circulation," Czech National Bank Working Paper Series No. 11.

Ikoku, Alvan. 2014. "Modeling and Forecasting Currency in Circulation for Liquidity Management in Nigeria," Central Bank of Nigeria Journal of Applied Statistics, Vol. 5, No. 1 , June.

Khiaonarong, Tanai. 2014. "Oversight Issues in Mobile Payments," IMF Working Paper No. WP/14/123, July. Washington: International Monetary Fund.

Koziński, Witold, and Tomasz Świst. 2015. "Short-term Currency in Circulation Forecasting for Monetary Policy Purposes - The Case of Poland," Financial Internet Quarterly eFinanse, Vol.11, No. 1.

Lang, Maroje, Davor Kunovac, Silvio Basač, and Željka Štaudinger. 2008. "Modelling of Currency outside Banks in Croatia," Croatian National Bank Working Paper, February 2008.

Mersch, Yves, Member of the Executive Board of the ECB. 2014. "Euro banknotes-a means of payment recognized worldwide," speech at the Bargeldsymposium of the Deutsche Bundesbank, Frankfurt, May 19.

Nield, Ian. 2006. "Changes to the Liquidity Management Regime," Reserve Bank of New Zealand: Bulletin, Vol. 69, No. 4, December. 
Norat, Mohamed Afzal. 2008. "Forecasting Banknotes," Bank of England, Centre for Central Banking Studies Handbook—No. 28, December.

Pierce, David A., Michael R. Grupe, and William P. Cleveland. 1984. "Seasonal Adjustment of the Weekly Monetary Aggregates: A Model-Based Approach," Journal of Business \& Economic Statistics, Vol. 2, No. 3, July.

Porter, Richard, and Ruth Judson. 1996. "The Location of U.S. Currency: How Much is Abroad?" Federal Reserve Bulletin, Vol. 82, 883-903, October.

Reserve Bank of New Zealand. 2006. "Review of the Reserve Bank of New Zealand's Liquidity Management Operations," consultation paper, March. . 2007. “Explaining New Zealand's Monetary Policy,” July.

Schaechter, Andrea. 2000. "Liquidity Forecasting," IMF, MAE Operational Paper MAE OP/00/7, November. Washington: International Monetary Fund.

Seitz, Franz. 1995. "The Circulation of Deutsche Mark Abroad," Discussion Papers of the Economic Research Group of the Deutsche Bundesbank, No. 1/95, May.

Stone, Mark. 1998. "Financial Infusion and Exiting from a Money Rule," IMF Working Paper 98/31, March. Washington: International Monetary Fund.

Tobin, James. 1956. "The Interest-Elasticity of Transactions Demand for Cash," Review of Economics and Statistics, Vol. 38, No. 3, August. 